\title{
First-mover disadvantage: the sovereign ratings mousetrap
}

\section{Patrycja Klusak $^{1}$ @ | Moritz Kraemer ${ }^{2}$ | Huong Vu ${ }^{3}$}

\author{
${ }^{1}$ Norwich Business School, University of East \\ Anglia and Bennett Institute for Public Policy, \\ University of Cambridge, UK \\ ${ }^{2}$ Goethe-University, Frankfurt, Germany and \\ SOAS University of London, UK \\ 3 University of Aberdeen, King's College, \\ Aberdeen, UK \\ Corresponding author: Email: \\ p.klusak@uea.ac.uk
}

Data availability: Please refer to Appendix Table 3 for a full list of episodes.

\begin{abstract}
Using 102 sovereigns rated by the three largest credit rating agencies (CRA), S\&P, Moody's and Fitch between January 2000 and January 2019, we document that the first-mover CRA (S\&P) in downgrades falls into a commercial trap. Namely, each sovereign downgrade by one notch by the first-mover CRA (S\&P) results in $2.4 \%$ increase in the probability of a rating contract being cancelled by the sovereign client. The more downgrades S\&P makes in a given month, the more their sovereign rating coverage falls relative to its rivals. Our results are more pronounced for downgrades on small sovereign borrowers than on large sovereign borrowers. This paper explores the interaction between three themes of the literature: herding behaviour amongst CRAs, issues of conflict of interest and ratings quality. Our empirical evidence gives credence to, and underscores the need for sovereign ratings to be made in an impartial way and independent of their commercial ramifications elsewhere in the CRA.

\section{KEYWORDS}

Sovereign credit ratings, herding behaviour, conflict of interest, solicitation

JEL CLASSIFICATION

G15, G24
\end{abstract}




\section{1 | INTRODUCTION AND SETTING OF THE PAPER}

Using global credit rating agencies (CRAs) including S\&P, Moody's, and Fitch we study whether the CRA which leads in issuing sovereign rating downgrades faces commercial implications such as loss of contracts and reduced market share. Contrary to popular belief, most sovereigns pay for ratings (i.e., solicited ratings; see S\&P, 2019a). While CRAs do not disclose financial results of individual business segments, such as sovereign ratings, the fact that most sovereign ratings are paid for would suggest that the sovereign business contributes positively to the bottom line of the CRAs proceeds, especially if one considers downstream business that results from the assignment of a sovereign rating. This can include state-owned companies or financial institutions, but also other ratings in a rated sovereign jurisdiction as well as supranationals whose creditworthiness depend partly on the financial promises made by member sovereigns

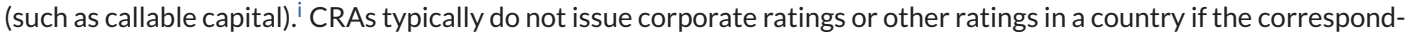
ing sovereign is not rated first. Therefore, the commercial impact of sovereign ratings for CRAs can be much larger than the relatively small number of rated sovereigns (as compared, for example to corporates) would suggest.

Sovereign credit ratings can determine countries' access to capital (Almeida et al., 2017; Cornaggia et al., 2017) and shape economic growth prospects (Chen et al., 2016). Unfavourable sovereign ratings can correlate with rising costs of credit and can hinder market access (Brunnermeier et al., 2016). As observed during the recent European sovereign debt crisis, sovereign rating downgrades can spill over to other asset classes and economically connected countries (Acharya et al., 2021; Augustin et al., 2018; Baum et al., 2016). ${ }^{i i}$ Therefore, understanding rating agencies' reaction functions on sovereign ratings is insightful for ratings users such as investors, policymakers and academics alike. A firmer sense of which CRA tends to be leading in times of changing credit quality can allow investors to make better and faster decisions for themselves and their clients.

Being first can cause a dilemma for a CRA. While being the first mover on an upgrade cycle is typically met with applause by the affected government, the reaction can be quite adverse if a government is faced with a downgrade for the first time. In some cases, the government may decide to cancel the contract with the downgrading CRA (e.g., Turkey withdrew its contract with S\&P in January 2013 after a series of downgrades).iii This has an immediate impact on the financial results of the CRA in question. In some cases, the CRA will react by withdrawing the rating at the issuer's request after communicating the final downgrade decision to the market. Where it considers that sufficient market interest exists in a sovereign rating, the CRA may choose to continue coverage in the form of an unsolicited, i.e. non-fee paying, rating. It loses income either way. In the case of maintaining an unsolicited rating, the CRA has to additionally continue to mobilise the necessary staff and resources for full credit surveillance.

In principle, none of this should affect the actual ratings that are issued. All CRAs insist that they keep commercial interest and analytical assessments separate, and supervisors continuously monitor that the corresponding walls of separation are effectively applied (S\&P, 2018; MIS, 2017). Since the financial crisis and the tightening regulation of the sector, those safeguards have been further strengthened (e.g., CRA Regulation in Europe; see Staikouras, 2012).iv This was in response to the doubt being cast on the CRAs' issuer-pay compensation structure (Efing and Hau, 2015; Wilson and Donnellan, 2016). However, analysts can come under immense pressure that may require a high degree of personal and professional resilience. ${ }^{v}$ CRAs need to choose whether to respond in a timely manner and to reflect the new information about the issue(r) (Berwart et al., 2016; Hill and Faff, 2010) at the cost of potentially losing a contract (if it is a negative assessment) or to rely on others being the leaders and perhaps losing their first-mover position in the market.

Earlier research supports the view that S\&P is considered the first mover, especially in downgrades (Flynn and Ghent, 2018; Güttler and Wahrenburg, 2007; Hill and Faff, 2010) and, contrary to its competitors, appears to have been particularly subjected to sovereign clients cancelling their contracts after a first mover downgrade. We observe this pattern in sovereigns as diverse as Turkey, Saudi Arabia, Italy, Portugal, Isle of Man, Guernsey, Tunisia, and Gabon (the latter four were then withdrawn by S\&P rather than surveyed on an unsolicited basis, although Guernsey was later reinstated upon signing a new ratings agreement). This anecdotal examination seems to suggest that further research 
into this complex subject is warranted. We propose the hypothesis that the first mover advantage may lead to a "commercial mousetrap": the first mouse gets squashed, while the second and third mouse share the cheese. We address the following question: 'Does the first downgrade mover incur a penalty by losing a contract with the sovereign?'

It could be argued that, by releasing prompt downgrades, a CRA serves the needs of ratings users (investors) but potentially harms the interests of issuers since reduction in creditworthiness could mean higher costs of credit and reduced economic prospects as well as a perceived threat to the prestige of the sovereign's political leaders. To the severity can be added the fact that sovereign downgrades might result in downgrades of other asset classes domiciled in the concerned country (Hill et al., 2017). Therefore, sovereigns might choose to cancel their contracts following a downgrade. To test this prediction, we identify the "punishment" as a withdrawal of sovereign contract or switch to the unsolicited rating following the sovereign downgrade. Additionally, we examine the direct effect of a sovereign downgrade on CRAs' sovereign rating coverage relative to rival CRAs. This measure helps us to reveal insights into the potential impact on the first-mover's market power. ${ }^{\mathrm{vi}}$

Our research benefits from a rich dataset of daily ratings for 102 countries jointly rated by the three global CRAs, including S\&P, Moody's and Fitch during the period between January 12000 and January 15 2019. Unlike the existing studies on the lead-lag relationship, we test the co-dependency of the biggest three CRAs simultaneously rather than in pairs (e.g., Güttler and Wahrenburg, 2007). We do this by comparing the episodes where all three CRAs have reflected a change in the trend of credit strength. By observing the direction of the rating changes (sovereign credit trend reversal) rather than simply their intensity, we are able to disentangle which CRA is the quickest to respond to the new information and incorporate it into the sovereign rating before it becomes a consensus view. In other words, we are able to deduce which rating action carries more information content, depending on whether it is leading or lagging behind rating actions by competitors. Additionally, by applying a rigorous identification strategy where, inter alia, the period between the first and the last mover does not exceed five years, we lower the possibility that a later rating action is a response to a different posterior development rather than a response to the same development that triggered the preceding rating action in the same direction by a competitor.

Under our identification strategy, there are 55 episodes of triple downgrades. This means that in 55 cases, all three major CRAs downgraded a given sovereign within five years, following stable ratings or upgrades in the five years prior to the beginning of this episode. We consider this situation as a negative credit trend reversal. During the same period of investigation, we account for 65 episodes of triple upgrades (positive credit trend reversals). Positive and negative trend reversals are observed for 73 sovereigns worldwide. This shows that a sovereign can be subject to several episodes of trend reversals during the 2000-2019 period.

Our Leadership Index calculated on the episodes highlights S\&P as the leader for both types of rating changes, particularly downgrades that cross the investment-speculative boundary "fallen angels". Moody's and Fitch tend to follow S\&P, with Moody's being slower than Fitch in catching up with S\&P. We also find more supporting evidence for S\&P's leadership revealed by the semiparametric Cox proportional hazard model. S\&P's leadership persists over the years and dominates particularly in EMEA and the Americas.

Our important findings lie in the test of the commercial 'mousetrap hypothesis', as we focus on the commercial consequences for the first mover CRA rather than its followers (e.g., Chen et al., 2019; Lugo et al., 2015). Specifically, we investigate the impact of sovereign downgrades by S\&P (the downgrade leader CRA in our data) on their future sovereign rating coverage and their probability of ratings contracts being withdrawn. We find that downgrades by the first-mover CRA, S\&P in particular, not only raise the likelihood that sovereign clients terminate rating contracts within the next three years by $2.4 \%$ but also cause S\&P's sovereign rating coverage relative to Moody's to decline by $1.2 \%$. Both obtained results are statistically significant at $1 \%$ level and economically meaningful.

Our work has implications for CRA regulators, policymakers and CRAs themselves. Considering the prominence of sovereign ratings in the political debate, risks faced by the sovereign analysts are arguably higher than for analysts of other asset classes. In order to uphold the integrity and relevance of the sovereign ratings process, every effort must be made to protect analysts from those potential non-analytical influences. First and foremost, this is the responsibility of the CRAs themselves. Analysts must remain effectively shielded from commercial corporate interests of the 
CRA itself through robust, transparent and uncompromising compliance rules separating analytics from the business. Analysts must also feel secure in the understanding that by expressing their analytical opinions and voting accordingly in credit committees, they will not in any indirect way impact their own career or, employment prospects at their firm. It falls with the purview of regulators to monitor the strict and unerring adherence to the latter and the spirit of effective compliance arrangements and investigate to what extent organisational or staffing changes at CRAs might be an expression of a conflict of interest within the CRA. ${ }^{\text {vii }}$

The rest of the paper is structured as follows. In Section 2 we provide a critical appraisal of the literature. Section 3 presents data and methodology. Section 4 summarises the empirical results and finally, Section 5 concludes the study.

\section{2 | LITERATURE REVIEW}

The topic of herding behaviour is an established and extensive area in finance literature. It has long been known that security analysts herd when making stock recommendations (Barber et al., 2001; Chen et al., 2018; Clement et al., 2005; Cooper et al., 2001; Hong et al., 2000; Jegadeesh and Kim, 2010). Theoretical models by Banerjee (1992), Graham (2003), Scharfstein and Stein (1990), and Trueman (1994) show that the decision to herd is influenced by the abilities, incentives and reputational considerations of analysts. Scharfstein and Stein (1990) suggest that managers herd because they want to maintain their reputation in the labour market. By mimicking the behaviour of others, managers send a signal that they rely on the same stimulus to make decisions and at the same time reassuring others of their status. This premise is empirically supported in the context of mutual fund managers (Raddatz and Schmukler 2013), equity analysts (Hong, et al., 2000), investment managers (Rajan, 2006), and pension fund managers (Da et al., 2018). Rajan (2006) finds that herding might act as an insurance protecting management against underperformance whereas Jegadeesh and Kim (2010) suggest analysts herd more when negative news is about to be announced to avoid standing out from the crowd.

Literature distinguishes between intentional and spurious herding. Intentional herding might arise when investors or/and firms realise their position in the market is inferior and therefore imitate the decisions of more informed and experienced players. "Hiding in the herd" might prevent them from being penalised for making a "wrong" decision (Scharfstein and Stein, 1990). Secondly, individuals might observe positive externality from imitating the behaviour of others, for example when they believe their peers have an information advantage (Chen et al., 2019; Graham, 2003). Finally, imitating behaviour of others might bring an increased pay-off with a rising number of agents behaving the same way (see Devenow and Welch, 1996).

Frijns and Huynh (2018) argue that analysts do not follow each other but their actions simply reflect access to the same information, which reduces the asymmetry gap between analysts, resulting in similar recommendations (Bushee et al., 2010; Tetlock, 2010). On the other hand, incentive theory suggests that media coverage might have a negative effect on herding as analysts will try to show their individualism by issuing decisions away from the consensus to improve their career prospects (Rees et al., 2014).

Lugo et al. (2015) suggest the first two theories are the most relevant in explaining herding behaviour amongst CRAs. Although, in theory, CRAs are not aware of the rating which will be issued by their competitors, once that information is publicly disclosed other CRAs might consolidate it into their own ratings (Mariano, 2012). Additionally, as evidenced by Griffin et al. (2013), S\&P and Moody's tend to make more strict initial credit assessments when they believe the rival's model to be less stringent. This finding suggests that CRAs account for competitors' views before the security is issued with the initial rating. Bar-Isaac and Shapiro (2013) develop a theoretical model suggesting that a CRA which makes a misjudged decision in contrast with the leader will be punished by the investors. Therefore, CRAs have a strong incentive to herd to protect their reputational capital (Lugo et al., 2015).

Spurious herding takes place when actions of managers correlate with each other due to underlying similarities such as educational background, professional experience, the processes in place or a regulatory climate which they 
are governed by (Chen at al., 2018). With respect to CRAs this theory would suggest that similar rating revisions (or lagged in a short time frame) are a result of homogeneity of the analysts.

The literature on lead-lag relationships in ratings applies two distinctive methodologies: (i) Granger causality models and (ii) Cox proportional hazard models. Güttler and Wahrenburg (2007) study biases in ratings and lead-lag relationships for near-to-default corporate issuers holding ratings from Moody's and S\&P between 1997-2004 using Granger causality models. viii The authors find that once S\&P (Moody's) changes its rating the probability of a rating change by the rival CRA significantly increases in magnitude in the short-time horizon (1-180 days). Alsakka and ap Gwilym (2010) extend this work by studying the herding behaviour on the sovereign level using 5 CRAs between 1994-2009. They find that S\&P (Fitch) is the most (least) independent among the CRAs while Moody's leads in upgrade episodes. Moreover, smaller Japanese CRAs generally follow larger CRAs, with the exception of downgrades when they lead Moody's.

In contrast with these studies, Chen et al. (2019) assume herding amongst CRAs to be heterogenous across sovereigns. Using 35 separate country regressions, the authors find that herding differs across countries and CRAs. Namely, all CRAs herd towards each other with no clear leader and follower which could be attributed to all countries. S\&P tends to lead in the majority of countries, which might suggest the CRA is more concerned with its reputational capital (Camanho et al., 2020). Surprisingly, Fitch leads rating revisions in more countries than Moody's, contrary to the reputational expectations proposed in Lugo et al. (2015). ${ }^{\text {ix }}$ Finally, Chen et al. (2019) support the finding of Lugo et al. (2015) suggesting that herding amongst CRAs is intentional.

In the second stream of literature, Güttler (2011) and Lugo et al. (2015) apply survival analysis methodology to assess how rating news by one CRA affects the intensity of a rating change by a rival CRA. Using S\&P and Moody's rated corporate issuers during 1994-2005, Güttler (2011) finds that preceding upgrade (downgrade) by one CRA leads to an increased intensity (one notch) of an upgrade (downgrade) by the rival CRA. Lugo et al. (2015) use the mortgage backed securities (MBS) market for three Big CRAs and the Cox proportional hazard models to examine how negative news by CRAs (downgrades, outlook and watchlist) affect future downgrades of rival CRAs during the financial crisis period (June 2007-July 2011). Their study captures the relative differences between the timing of rating actions by CRAs and their convergence similar to Güttler (2011). They find that the hazard of S\&P and Moody's downgrade/rating revision is more influenced by a downgrade/revision of one another than by that of Fitch. This finding is consistent with the notion that the likelihood to herd increases with the reputation of the leader (Mariano, 2012) (S\&P and Moody's have a longer track-record and considerably larger market coverage than Fitch and are therefore often considered more relevant).

A limitation of many papers investigating the lead-lag relationship in ratings is that they are confined to testing pairs of CRAs in isolation using a restricted number of controls. This view is simplistic and does not account for the whole spectrum of the CRA market where relationships amongst CRAs are multidimensional. ${ }^{x}$ Second, the identification of leader-followers is not rigorous enough to rule out the possibility of spurious lead-lag relationships due to CRAs reacting to different developments in sovereign credit strength. In this paper, we overcome these shortcomings by applying a more rigorous strategy to identify the leading CRAs. Finally, despite documenting the strong evidence for the lead-lag relationship in sovereign ratings among CRAs, prior studies seem to neglect the question of whether there is a significant economic cost (benefit) to the leading (following) CRAs. We contribute to the rating literature by filling this void.

\section{3 | DATA AND METHODOLOGY}

\section{1 | Sample selection}

In this paper, we collect a global dataset of daily foreign currency sovereign issuer long term credit ratings assigned by the three global CRAs, including Standard \& Poor's, Moody's and Fitch in the period 1 January 2000 - 15 
January 2019. Our rating data are obtained from Bloomberg. In order to examine the lead-lag relationship among CRAs, we only consider triple rating observations, i.e. where all three CRAs assign ratings to the same sovereigns. Ratings are converted from alphanumeric symbols to numbers using a 20-notch conversion scale. The highest rating category AAA/Aaa receives the highest value of 20, while ratings below CCC-/Caa3 receive the lowest value of one. See Appendix Table A1.

Similar to the literature (Berwart et al., 2016, Hill and Faff, 2010), our analyses focus on rating changes, specifically downgrades and upgrades. In order to identify the leader-follower, we require that the rating actions by both the leader and the followers are in the same direction, up or down and in a direction different from the previous direction, which will presumably reflect CRAs' reactions to the same developments in sovereign credit strength. In this respect, our approach is more rigorous than Hill and Faff (2010). ${ }^{x i}$ Specifically, we require that CRAs' rating actions are associated with a directional reversal of a previously observed credit trend, or the changes in ratings after a long period when ratings by all the three CRAs had remained stable. We define a reversal of a credit trend as a credit episode in which all the three CRAs upgrade (downgrade) the ratings on the sovereign after the last of all three CRAs had previously downgraded (upgraded) the ratings. Such an episode reflects the fact that eventually all the three CRAs agree the trend in the credit quality of the sovereign has reversed, i.e. it has improved after a period of deterioration (or it has deteriorated after a period of improvement), and all the three CRAs react in the same manner by upgrading (downgrading) the ratings. ${ }^{\text {xii }}$

Alongside the credit trend reversal, we also identify credit episodes where all the three CRAs upgrade (downgrade) ratings on the sovereigns after a prolonged period of no changes in ratings. We require that the no-change period be at least five years. xiii All rating actions must have occurred after 1 January 2000 and before 15 January 2019 for all sovereigns in the dataset. ${ }^{\text {xiv }}$ Each rating reversal episode must last less than five years from the first to the third rating action to be counted (we relax this assumption later, see Table 2). We impose the five-year horizon on our data because it is increasingly likely that rating actions by different CRAs which lie more than five years apart reflect the CRAs' reactions to new and different developments impacting on the sovereign's credit strength. In other words, we assume that if not all three CRAs have reacted in the same direction within five years, there was no consensus across the three CRAs that the factor that may have led the first agency to change the rating truly constituted a material difference in a sovereign's credit strength. We rely on rating changes only and do not analyse outlooks on ratings as these signals merely indicate where ratings might be moving in the next year or two (S\&P, 2014). ${ }^{\mathrm{x}}$

There are three grounds of our preference for a five-year window. First, anything as short as 1-15 days in Alsakka and ap Gwilym (2010) does not appreciate the practice of how CRAs operate to issue sovereign ratings. Typically, CRAs release sovereign rating once a year. This is a common practice driven by the regulatory requirement to opine at least at a yearly rhythm. For instance, Article 8 A of EU CRA regulation requires that CRAs release a sovereign rating calendar at the end of each December for the following twelve months where dates (maximum three) for the publications of sovereign ratings and related outlooks are revealed (EC, 2011). Moreover, when a ratings committee convenes it may opt for a stepwise revision where outlook or watch status changes before the actual rating change is recorded (e.g., rather than announcing an immediate (positive) rating action a committee might issue a positive outlook in year one and an actual upgrade in year two). This process might take several years and given that the calendars differ from one agency to the next, we take that a typical length of an episode should be three years at a minimum and can extend up to five years.

Second, Hill and Faff (2010) apply a 21-day window from the last rating event. However, they focus on crisis situations at or near default. Our set up differs significantly as we focus on capturing the turning points of credit quality at all rating levels, not only fast-moving distress situations in the B category or below. xvi

Finally, credit quality changes more slowly in the sovereign than the corporate world. Companies might experience shifts according to quarterly financial results that are visible to all investors and CRAs at the same time. There is no comparable audited reporting of data for sovereigns. Data required for rating sovereigns originates from various sources at different points of time (S\&P, 2013). Additionally, if troubled sovereigns receive support from central banks or multilateral lenders such as the International Monetary Fund (IMF) or European Stability Mechanism (ESM) or raise 


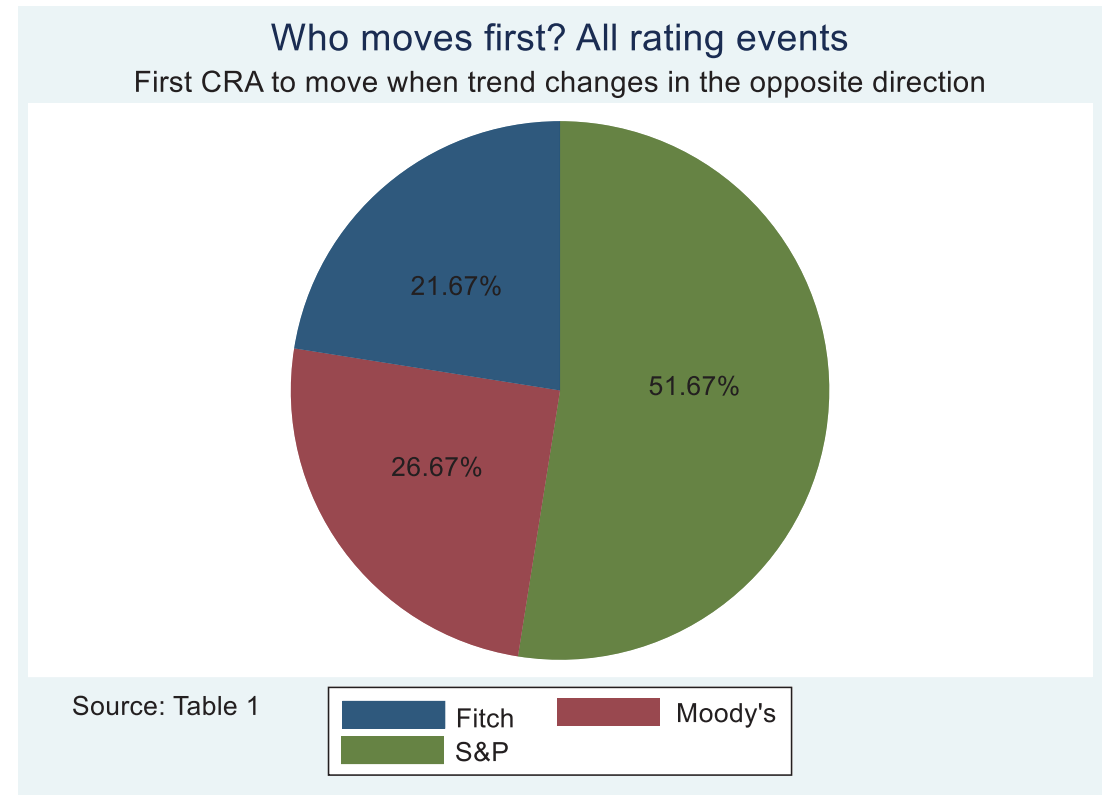

FIG URE 1 The frequency of being a first mover in an episodes of sovereign credit trend reversal [Color figure can be viewed at wileyonlinelibrary.com]

taxes or confiscate deposits, slowing down the decline in creditworthiness. Countries experiencing credit problems cannot raise prices to offset their difficulties. Therefore, underlying volatility and shocks for sovereigns are much smaller than for corporates making them more stable. ${ }^{\text {xvii }}$ Sovereign ratings show considerably higher stickiness compared to corporate ratings. For this reason, one needs to allow more time to see the change in sovereign credit quality. For robustness check, we redefine episodes in each of five different time horizons ranging from one year to five years and report the results in Table 2.

Unlike the common approach of examining lead-lag relationship by pairs of CRAs in the literature (Alsakka and ap Gwilym, 2010; Berwart et al., 2016; Chen et al., 2019; Güttler and Wahrenburg, 2007), we examine the lead-lag relationship between three CRAs simultaneously. Accordingly, we do not examine episodes in which only two CRAs change the ratings. ${ }^{\text {xviii }}$ Therefore, we require that each episode in our sample must incorporate rating changes by all three CRAs. Accordingly, "leader" is defined as the CRA taking the first rating action in a rating reversal episode and "follower" is the CRA taking the second and the third rating action in an episode. Our approach has a number of advantages over related studies. First, it enables us to identify the leading CRA by looking at the relative timeliness of their rating actions in comparison with their competitors. Second, we minimise the likelihood of spurious analyses due to grouping rating actions associated with different trends in the sovereign's credit quality.

We identify 120 episodes of credit trend reversal, including 55 downgrade episodes and 65 upgrade episodes in 73 countries worldwide. Although a majority of the countries encounter only one episode during the sample period, there are 32 countries experiencing multiple episodes of both types (downgrades and upgrades), accounting for $43.8 \%$ of 73 countries in the sample. Brazil and Greece are the two countries where episodes of credit trend reversal occur most frequently (4 times for Brazil and 5 times for Greece).

Figure 1 depicts the frequency of being the first mover for the three leading CRAs. S\&P leads 63 out of 120 episodes ( $52 \%$ of the time), making them the most frequent first mover in all the episodes of both types. Moody's and Fitch tend to follow S\&P when new developments signal a reversal in the trends of the sovereigns' credit strength. When looking into the types of the episodes, we find that S\&P takes rating actions more promptly than Moody's and Fitch when credit trends change in both positive and negative directions. S\&P leads Moody's and Fitch $62 \%$ of the time in the 


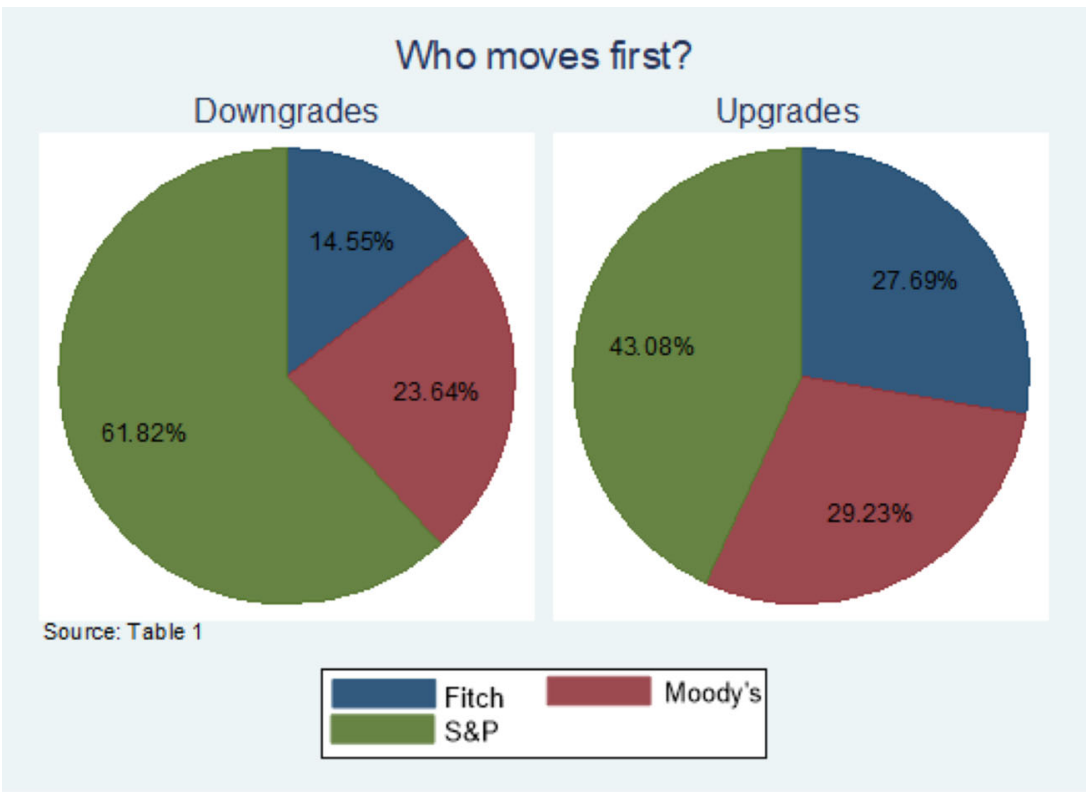

FIGURE 2 The frequency of being a first mover in an episode of positive (negative) sovereign credit trend reversal. Downgrades indicate episodes of negative sovereign credit trend reversal and upgrades indicate episodes of positive sovereign credit trend reversals [Color figure can be viewed at wileyonlinelibrary.com]

case of downgrades and $43 \%$ of the time in the case of upgrades (See Figure 2). Our preliminary results corroborate the findings in Alsakka and ap Gwilym (2010) that S\&P is the CRA most independent from actions by other CRAs, especially in the case of downgrades.

In order to answer the question of how long it takes for a CRA to catch up with the leader when they are a follower in an episode, we look at their time-lag by calculating the number of days from the day the leader raises (lowers) the rating to the day the follower takes the same action. The time lag varies from one day to 1825 days. xix Figure 3 summarises the median time-lag for each CRA. Fitch tends to move faster than Moody's in catching up with the leader. Specifically, the median number of days for Fitch to catch up with the first mover is 210 days while it is 364 days for Moody's. Moody's typically follows slower than Fitch and S\&P in both upgrade episodes and downgrade episodes. It takes 433 (313) days for Moody's to catch up with the first mover on upgrading (downgrading).

Finally, Figure 4 plots the distribution of credit trend reversal episodes over the years. The horizonal axis represents the year when the first-mover CRA announces a rating action. In general, the frequency distributions of upgrade episodes and downgrades episodes stretch evenly across the years. Positive credit reversals become more common after 2008, whereas negative credit reversals remain stable over the years with the only exception of a spike in 2000. On average, there are more or less 5 positive credit episodes per year and 3-4 negative credit episodes per year.

\section{2 | The multivariate analysis of lead-lag relationship}

In order to examine the interdependence among the three CRAs, we employ a Cox proportional hazard model. The Cox proportional hazard model has been used to analyse the timing of rating downgrades on other asset classes such as ABS Home Equity Loans (Lugo et al., 2015) and corporate bonds (Mählmann, 2011). Our Cox hazard rate model examines the downgrade (upgrade) rate for a sovereign $i$, which is denoted $h_{i}(t)$ and specified by the following 


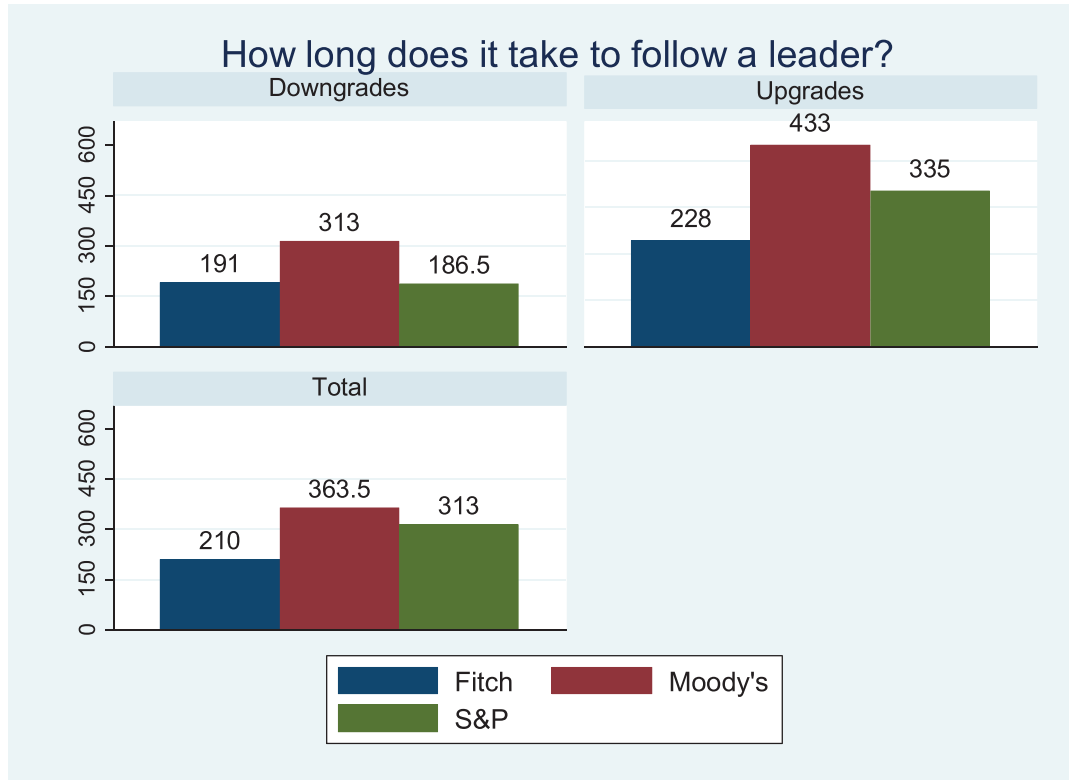

FIGURE 3 The median number of days for a follower CRA to catch up with the first mover in an episode of sovereign credit trend. Downgrades indicate episodes of negative sovereign credit trend reversal and upgrades indicate episodes of positive sovereign credit trend reversals. Total indicates episodes of credit trend reversal in both directions [Color figure can be viewed at wileyonlinelibrary.com]

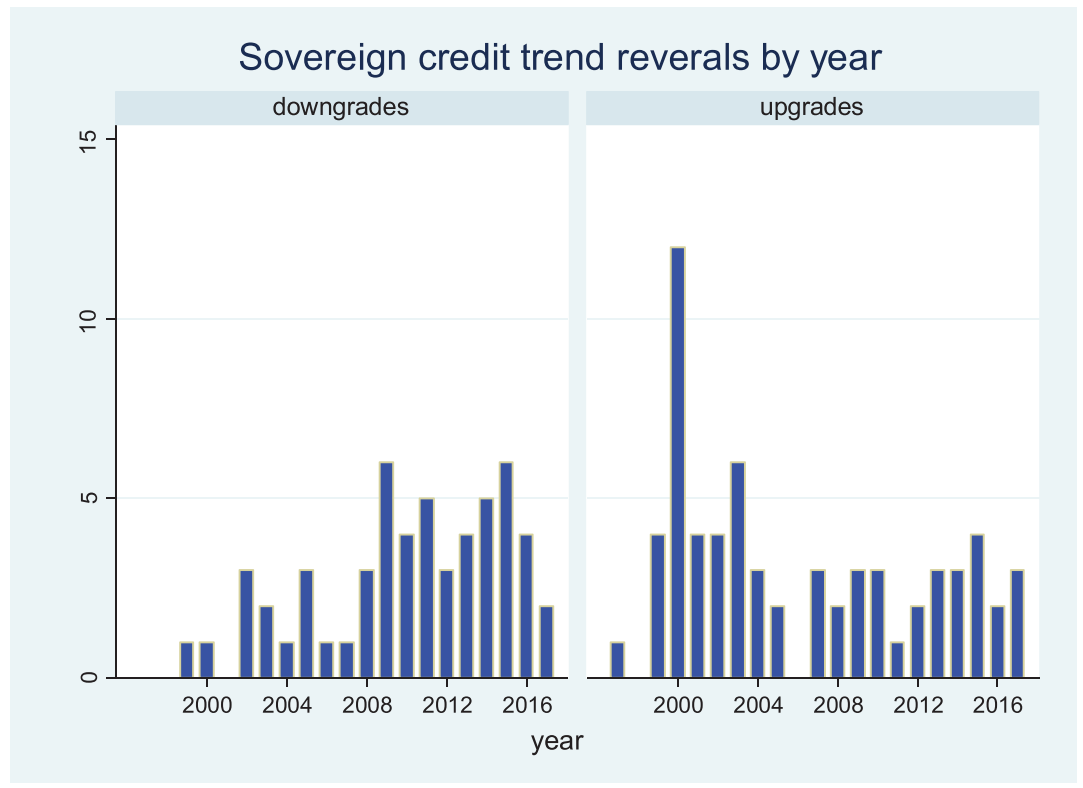

FIGURE 4 The distribution of episodes of sovereign credit trend reversal by year. Calculations are based on Appendix Table A2 [Color figure can be viewed at wileyonlinelibrary.com] 
TAB LE 1 Who moves first?

\begin{tabular}{|c|c|c|c|c|c|c|c|c|c|}
\hline & \multicolumn{3}{|c|}{$\begin{array}{l}\text { Changes in trend (both } \\
\text { directions) }\end{array}$} & \multicolumn{3}{|c|}{$\begin{array}{l}\text { Changes in trend (upgrades } \\
\text { only) }\end{array}$} & \multicolumn{3}{|c|}{$\begin{array}{l}\text { Changes in trend } \\
\text { (downgrades only) }\end{array}$} \\
\hline & $S \& P$ & Moody's & Fitch & $\mathrm{S} \& \mathrm{P}$ & Moody's & Fitch & $\mathrm{S} \& \mathrm{P}$ & Moody's & Fitch \\
\hline \multicolumn{10}{|c|}{ PANEL I: ALL OBSERVATIONS } \\
\hline First mover (\%) & 52 & 27 & 22 & 43 & 29 & 28 & 62 & 24 & 15 \\
\hline Second mover (\%) & 26 & 31 & 44 & 26 & 26 & 48 & 25 & 36 & 40 \\
\hline Third mover (\%) & 23 & 43 & 34 & 31 & 45 & 25 & 13 & 40 & 45 \\
\hline Observations & 120 & 120 & 120 & 65 & 65 & 65 & 55 & 55 & 55 \\
\hline Leadership Index & 1.71 & 2.16 & 2.13 & 1.88 & 2.15 & 1.97 & 1.51 & 2.16 & 2.31 \\
\hline $\begin{array}{l}\text { Wilcoxon signed-rank } \\
\text { test }\end{array}$ & & $-3.35^{* * *}$ & $-3.16^{* *}$ & & -1.52 & -0.48 & & $-3.39^{* * *}$ & $-3.98^{* * *}$ \\
\hline \multicolumn{10}{|l|}{ PANEL II: REGIONS } \\
\hline \multicolumn{10}{|l|}{ EMEA (ALL PERIODS) } \\
\hline Observations & 78 & 78 & 78 & 40 & 40 & 40 & 38 & 38 & 38 \\
\hline Leadership Index & 1.63 & 2.16 & 2.21 & 1.85 & 2.10 & 2.05 & 1.39 & 2.21 & 2.37 \\
\hline $\begin{array}{l}\text { Wilcoxon signed-rank } \\
\text { test }\end{array}$ & & $-2.89^{* *}$ & $-3.63^{* * *}$ & & -0.92 & -0.97 & & $-3.21^{* *}$ & $-4.13^{* * *}$ \\
\hline \multicolumn{10}{|c|}{ AMERICAS (ALL PERIODS) } \\
\hline Observations & 29 & 29 & 29 & 16 & 16 & 16 & 13 & 13 & 13 \\
\hline Leadership Index & 1.76 & 2.28 & 1.96 & 1.75 & 2.44 & 1.81 & 1.77 & 2.08 & 2.15 \\
\hline $\begin{array}{l}\text { Wilcoxon signed-rank } \\
\text { test }\end{array}$ & & $-2.12^{* *}$ & -0.69 & & $-1.92^{*}$ & -0.11 & & -0.92 & -0.91 \\
\hline
\end{tabular}

\section{ASIA PACIFIC (ALL PERIODS)}

$\begin{array}{llllllllll}\text { Observations } & 13 & 13 & 13 & 9 & 9 & 9 & 4 & 4 & 4 \\ \text { Leadership Index } & 2.08 & 1.92 & 2.00 & 2.22 & 1.89 & 1.89 & 1.75 & 2.00 & 2.25 \\ \begin{array}{l}\text { Wilcoxon signed-rank } \\ \text { test }\end{array} & & 0.25 & 0.29 & & 0.55 & 0.81 & & -0.38 & -0.56 \\ \end{array}$

\section{PANEL III: PERIODS}

\section{0-2004 (ALL REGIONS)}

$\begin{array}{llllllllll}\text { Observations } & 42 & 42 & 42 & 34 & 34 & 34 & 8 & 8 & 8 \\ \begin{array}{l}\text { Leadership Index } \\ \begin{array}{l}\text { Wilcoxon signed-rank } \\ \text { test }\end{array}\end{array} & 1.95 & 2.12 & 1.93 & 2.03 & 2.06 & 1.91 & 1.63 & 2.37 & 2.00 \\ \quad & -0.72 & 0.14 & & -0.03 & 0.45 & & -1.51 & -0.58\end{array}$

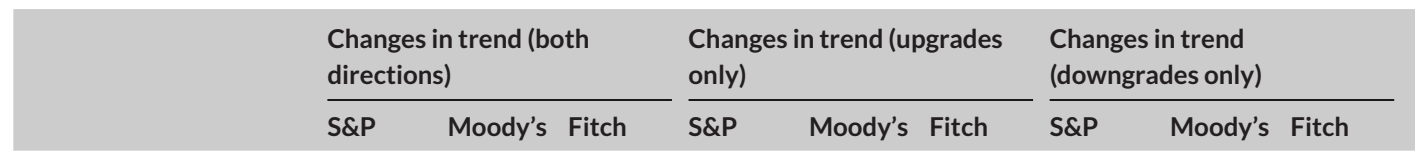

\section{5-2009 (ALL REGIONS)}

\begin{tabular}{llllllllll} 
Observations & 24 & 24 & 24 & 10 & 10 & 10 & 14 & 14 & 14 \\
Leadership Index & 1.46 & 2.42 & 2.13 & 1.60 & 2.20 & 2.20 & 1.36 & 2.57 & 2.07 \\
$\begin{array}{l}\text { Wilcoxon signed-rank } \\
\text { test }\end{array}$ & & $-3.05^{* * *}$ & $-2.90^{* * *}$ & & -1.31 & -1.46 & & $-2.83^{* * *}$ & $-2.67^{* * *}$ \\
\hline
\end{tabular}


TABLE 1 (Continued)

\begin{tabular}{|c|c|c|c|c|c|c|c|c|c|}
\hline & \multicolumn{3}{|c|}{$\begin{array}{l}\text { Changes in trend (both } \\
\text { directions) }\end{array}$} & \multicolumn{3}{|c|}{$\begin{array}{l}\text { Changes in trend (upgrades } \\
\text { only) }\end{array}$} & \multicolumn{3}{|c|}{$\begin{array}{l}\text { Changes in trend } \\
\text { (downgrades only) }\end{array}$} \\
\hline & $S \& P$ & Moody's & Fitch & $S \& P$ & Moody's & Fitch & $S \& P$ & Moody's & Fitch \\
\hline \multicolumn{10}{|c|}{ 2010-2014 (ALL REGIONS) } \\
\hline Observations & 33 & 33 & 33 & 12 & 12 & 12 & 21 & 21 & 21 \\
\hline Leadership Index & 1.82 & 1.91 & 2.27 & 1.92 & 2.25 & 1.83 & 1.76 & 1.71 & 2.52 \\
\hline $\begin{array}{l}\text { Wilcoxon signed-rank } \\
\text { test }\end{array}$ & & -0.37 & $-1.75^{*}$ & & -0.86 & 0.25 & & 0.22 & $-2.20^{* *}$ \\
\hline
\end{tabular}

2015-2018 (ALL REGIONS)

$\begin{array}{llllllllll}\text { Observations } & 21 & 21 & 21 & 9 & 9 & 9 & 12 & 12 & 12 \\ \text { Leadership Index } & 1.33 & 2.33 & 2.29 & 1.56 & 2.33 & 2.11 & 1.17 & 2.33 & 2.42 \\ \begin{array}{l}\text { Wilcoxon signed-rank } \\ \text { test }\end{array} & & -2.90^{* * *} & -2.96^{* * *} & & -1.47 & -1.25 & & -2.81^{* * *} & -2.83^{* * *} \\ \end{array}$

PANEL IV: SIZE OF BORROWING

SMALL BORROWERS (LESS THAN \$100 BIL. OF SOVEREIGN DEBT IN 2018)

$\begin{array}{llllllllll}\text { Observations } & 79 & 79 & 79 & 41 & 41 & 41 & 38 & 38 & 38 \\ \text { Leadership Index } & 1.62 & 2.29 & 2.08 & 1.71 & 2.37 & 1.93 & 1.53 & 2.21 & 2.24 \\ \begin{array}{l}\text { Wilcoxon signed-rank } \\ \text { test }\end{array} & & -3.83^{* * *} & -2.87^{* * *} & & -2.49^{* *} & -1.07 & & -2.94^{* * *} & -2.97^{* * *} \\ & & & & & & & & & \end{array}$

\begin{tabular}{|c|c|c|c|c|c|c|c|c|c|}
\hline Observations & 41 & 41 & 41 & 24 & 24 & 24 & 17 & 17 & 17 \\
\hline Leadership Index & 1.88 & 1.90 & 2.22 & 2.17 & 1.79 & 2.04 & 1.47 & 2.06 & 2.47 \\
\hline $\begin{array}{l}\text { Wilcoxon signed-rank } \\
\text { test }\end{array}$ & & -0.42 & -1.45 & & 0.85 & 0.61 & & $-1.71^{*}$ & $-2.75^{* * *}$ \\
\hline
\end{tabular}

Note: This Table presents distribution of trend changes across CRAs, regions, times and issuers' size of the debt issuance. Regions include Europe, Middle East, Central Asia (EMEA), the Americas, and Asia Pacific. Small (large) borrower relates to a sovereign with less than (more than) $\$ 100$ billion of sovereign debt outstanding in 2018 . The Leadership Index represents the sample mean rank of each CRA. It takes value 1 if CRA is the first-mover in a credit trend reversal episode, value 2 if CRA is the second-mover and value 3 if CRA is the third-mover. We also distinguish CRA's Leadership Index in upgrade episodes versus downgrade episodes. The Wilcoxon sign-rank test reports the z-statistic on the Wilcoxon matched-pairs signed-ranks test for the null hypothesis that the rank difference between S\&P and Moody's (Fitch) is zero. Significance levels are: ${ }^{* * *} \mathrm{p}<1 \%,{ }^{* *}$ $p<5 \%,{ }^{*} p<10 \%$. Refer to Appendix Table A3 for a full list of episodes.

semi-parametric regression model:

$$
h_{i}(t)=h_{0}(t) e^{(\beta X)}
$$

Where $h_{0}(t)$ is the baseline hazard, which will be left unestimated, and the regression coefficients $\beta$ will be estimated from our dataset.

Under our Cox proportional hazard model, we define event by either downgrade or upgrade and measure the time to the first event, i.e. downgrade (upgrade), by the number of elapsed days since the onset of the downgrade (upgrade) risk, which we set to be the first day of our sample period ( $1^{\text {st }}$ January 2000) or the first day the rating is assigned if the initial rating assignment occurs after $1^{\text {st }}$ January 2000 . The sovereign exits the sample at the first occurrence of the first downgrade (upgrade) by the analysed CRA. For sovereigns experiencing multiple episodes of the same type, i.e. multiple downgrade episodes or multiple upgrade episodes, we only examine the earliest episodes. This data structure 
TA B LE 2 Leadership Index under different timespans between first and last mover

\begin{tabular}{|c|c|c|c|c|c|}
\hline \multicolumn{6}{|l|}{ Panel I S\&P } \\
\hline $\begin{array}{l}\text { Maximum time elapsed between first and last rating mover } \\
\text { to qualify as single episode }\end{array}$ & 1 year & 2 years & 3 years & 4 years & 5 years \\
\hline $\begin{array}{l}\text { Total number of episodes (all periods, regions, both rating } \\
\text { directions) }\end{array}$ & 52 & 88 & 106 & 116 & 120 \\
\hline $\begin{array}{l}\text { Total Leadership Index (all periods, regions, both rating } \\
\text { directions) }\end{array}$ & 1.75 & 1.70 & 1.69 & 1.72 & 1.71 \\
\hline Leadership: Upgrades only (all periods, regions) & 1.92 & 1.93 & 1.86 & 1.87 & 1.88 \\
\hline Leadership: Downgrades only (all periods, regions) & 1.61 & 1.48 & 1.48 & 1.53 & 1.51 \\
\hline EMEA (all periods, all rating directions) & 1.59 & 1.58 & 1.60 & 1.65 & 1.63 \\
\hline Americas (all periods, all rating directions) & 2.06 & 1.86 & 1.80 & 1.75 & 1.76 \\
\hline Asia \& Pacific (all periods, all rating directions) & 1.67 & 2.11 & 2.00 & 2.08 & 2.08 \\
\hline 2000-2004 (all regions, both rating directions) & 1.94 & 2.04 & 2.00 & 1.98 & 1.95 \\
\hline 2005-2009 (all regions, both rating directions) & 1.67 & 1.42 & 1.40 & 1.45 & 1.45 \\
\hline 2010-2014 (all regions, both rating directions) & 2.07 & 1.86 & 1.76 & 1.84 & 1.82 \\
\hline 2015-2018 (all regions, both rating directions) & 1.23 & 1.35 & 1.33 & 1.33 & 1.33 \\
\hline \multicolumn{6}{|l|}{ Panel II Moody's } \\
\hline $\begin{array}{l}\text { Maximum time elapsed between first and last rating mover } \\
\text { to qualify as single episode }\end{array}$ & 1 year & 2 years & 3 years & 4 years & 5 years \\
\hline $\begin{array}{l}\text { Total number of episodes (all periods, regions, both rating } \\
\text { directions) }\end{array}$ & 52 & 88 & 106 & 116 & 120 \\
\hline $\begin{array}{l}\text { Total Leadership index (all periods, regions, both rating } \\
\text { directions) }\end{array}$ & 2.06 & 2.17 & 2.16 & 2.13 & 2.16 \\
\hline Leadership: Upgrades only (all periods, regions) & 2.08 & 2.11 & 2.16 & 2.15 & 2.15 \\
\hline Leadership: Downgrades only (all periods, regions) & 2.04 & 2.23 & 2.17 & 2.10 & 2.16 \\
\hline EMEA (all periods, all rating directions) & 2.00 & 2.17 & 2.16 & 2.12 & 2.15 \\
\hline Americas (all periods, all rating directions) & 2.06 & 2.23 & 2.24 & 2.25 & 2.28 \\
\hline Asia \& Pacific (all periods, all rating directions) & 2.67 & 2.00 & 2.00 & 1.92 & 1.92 \\
\hline 2000-2004 (all regions, both rating directions) & 2.06 & 2.04 & 2.06 & 2.10 & 2.12 \\
\hline 2005-2009 (all regions, both rating directions) & 2.22 & 2.47 & 2.50 & 2.36 & 2.42 \\
\hline 2010-2014 (all regions, both rating directions) & 1.64 & 1.91 & 1.93 & 1.87 & 1.9 \\
\hline 2015-2018 (all regions, both rating directions) & 2.38 & 2.35 & 2.33 & 2.33 & 2.33 \\
\hline \multicolumn{6}{|l|}{ Panel III Fitch } \\
\hline $\begin{array}{l}\text { Maximum time elapsed between first and last rating mover } \\
\text { to qualify as single episode }\end{array}$ & 1 year & 2 years & 3 years & 4 years & 5 years \\
\hline $\begin{array}{l}\text { Total number of episodes (all periods, regions, both rating } \\
\text { directions) }\end{array}$ & 52 & 88 & 106 & 116 & 120 \\
\hline $\begin{array}{l}\text { Total Leadership Index (all periods, regions, both rating } \\
\text { directions) }\end{array}$ & 2.17 & 2.11 & 2.14 & 2.14 & 2.13 \\
\hline Leadership: Upgrades only (all periods, regions) & 2.00 & 1.95 & 1.98 & 1.97 & 1.97 \\
\hline Leadership: Downgrades only (all periods, regions) & 2.32 & 2.27 & 2.33 & 2.35 & 2.31 \\
\hline EMEA (all periods, all rating directions) & 2.37 & 2.23 & 2.23 & 2.21 & 2.21 \\
\hline Americas (all periods, all rating directions) & 1.89 & 1.91 & 1.96 & 2.00 & 1.97 \\
\hline
\end{tabular}


TABLE 2 (Continued)

\begin{tabular}{|c|c|c|c|c|c|}
\hline \multicolumn{6}{|l|}{ Panel III Fitch } \\
\hline $\begin{array}{l}\text { Maximum time elapsed between first and last rating mover } \\
\text { to qualify as single episode }\end{array}$ & 1 year & 2 years & 3 years & 4 years & 5 years \\
\hline Asia \& Pacific (all periods, all rating directions) & 1.67 & 1.89 & 2.00 & 2.00 & 2.00 \\
\hline 2000-2004 (all regions, both rating directions) & 2.00 & 1.93 & 1.94 & 1.93 & 1.93 \\
\hline 2005-2009 (all regions, both rating directions) & 2.11 & 2.11 & 2.10 & 2.18 & 2.13 \\
\hline 2010-2014 (all regions, both rating directions) & 2.29 & 2.23 & 2.31 & 2.28 & 2.27 \\
\hline 2015-2018 (all regions, both rating directions) & 2.31 & 2.25 & 2.29 & 2.29 & 2.29 \\
\hline
\end{tabular}

Note: In this Table we re-define the episodes for three CRAs within windows ranging from one year to five years. We report Leadership Index for upgrades, downgrades, regions as well as sub-periods.

TAB LE 3 Rising Stars and Fallen Angels

\begin{tabular}{|c|c|c|c|}
\hline \multicolumn{4}{|c|}{ PANEL I: RISING STARS } \\
\hline & S\&P rank & Moody's rank & Fitch rank \\
\hline First & $33 \%$ & $27 \%$ & $40 \%$ \\
\hline Second & $47 \%$ & $20 \%$ & $33 \%$ \\
\hline Third & $20 \%$ & $53 \%$ & $27 \%$ \\
\hline Episodes & 15 & 15 & 15 \\
\hline Leadership Index & 1.87 & 2.27 & 1.87 \\
\hline \multicolumn{4}{|c|}{ PANEL II: FALLEN ANGELS } \\
\hline First & $80 \%$ & $20 \%$ & $0 \%$ \\
\hline Second & $10 \%$ & $50 \%$ & $40 \%$ \\
\hline Third & $10 \%$ & $30 \%$ & $60 \%$ \\
\hline Episodes & 10 & 10 & 10 \\
\hline Leadership Index & 1.3 & 2.1 & 2.6 \\
\hline
\end{tabular}

Note: This Table presents rank of each CRA as first mover, second mover and the last mover in the episodes where an investment-speculative grade boundary (BBB-/Baa3 - BB+/Ba1) has been crossed. Panel I lists episodes when sovereigns have been uplifted from a speculative grade status to an investment grade (Rising Stars), whereas Panel II lists episodes when sovereigns were downgraded from an investment grade to a speculative grade (Fallen Angels). Refer to Appendix Table A4 for a full list of episodes.

causes 12 upgrade episodes and 4 downgrade episodes to be excluded from the estimation. For each CRA from which the downgrade (upgrade) hazard is being analysed on the LHS of the model, the RHS variable (covariate $X$ ) is a binary one that takes value of unity if another CRA has already downgraded (upgraded) the sovereigns, zero otherwise. We utilise a dataset of 73 countries experiencing 43 episodes of negative credit trend reversal (downgrade episodes) and 61 episodes of positive credit trend reversal (upgrade episodes).

Following Lugo et al. (2015), for each CRA, we estimate three models: two models examine the effect of the downgrade (upgrade) by each rival CRA and one model examines the joint effect of the downgrades (upgrades) by both rival CRAs. The general prediction for interdependence implies that the downgrade (upgrade) hazard by a given CRA increases with the presence of an earlier similar rating action from the rival CRA. We predict that S\&P is the least dependent CRA, particularly in the episodes of negative credit trend reversal. Therefore, we expect to observe strong evidence that the intensity of downgrades (upgrades) by Moody's and Fitch (followers) is influenced by similar actions by S\&P (the leader). We also expect to find less (or no) evidence that the intensity of downgrades (upgrades) by S\&P 
TAB LE 4 Cox Proportional Hazard Models - Eq. (1)

\begin{tabular}{|c|c|c|c|c|c|c|c|c|c|}
\hline \multicolumn{4}{|c|}{ PANEL I: DOWNGRADES } & \multirow{2}{*}{\multicolumn{3}{|c|}{ Moody's }} & \multirow{2}{*}{\multicolumn{3}{|c|}{ Fitch }} \\
\hline \multirow[b]{2}{*}{ Downgraded by } & \multicolumn{3}{|l|}{ S\&P } & & & & & & \\
\hline & (1) & (2) & (3) & (4) & (5) & (6) & (7) & (8) & (9) \\
\hline \multirow[t]{2}{*}{$S \& P$} & & & & $3.248^{* * *}$ & & $2.625^{* * *}$ & $3.869^{* * *}$ & & $3.385^{* * *}$ \\
\hline & & & & (9.78) & & $(6.54)$ & $(10.72)$ & & (8.39) \\
\hline \multirow[t]{2}{*}{ Moody's } & $3.354^{* * *}$ & & $2.735^{* * *}$ & & & & & $3.642^{* * *}$ & $1.679^{* * *}$ \\
\hline & (8.01) & & $(5.67)$ & & & & & (8.61) & (3.43) \\
\hline \multirow[t]{2}{*}{ Fitch } & & $3.002^{* * *}$ & $1.614^{* * *}$ & & $3.289^{* * *}$ & $1.643^{* * *}$ & & & \\
\hline & & $(6.54)$ & $(2.86)$ & & (8.69) & (3.64) & & & \\
\hline \multirow[t]{2}{*}{ CRA rating } & $-0.0901^{* *}$ & $-0.0866^{* *}$ & $-0.0899^{* *}$ & $-0.154^{* * *}$ & $-0.114^{*}$ & $-0.129^{* *}$ & $-0.145^{* * *}$ & $-0.0917^{*}$ & $-0.0976^{*}$ \\
\hline & $(-2.02)$ & $(-1.96)$ & $(-1.98)$ & $(-2.72)$ & $(-1.89)$ & $(-2.08)$ & $(-2.66)$ & $(-1.76)$ & $(-1.69)$ \\
\hline Other controls & Yes & Yes & Yes & Yes & Yes & Yes & Yes & Yes & Yes \\
\hline Observations & 280587 & 280587 & 280587 & 290074 & 290074 & 290074 & 289372 & 289372 & 289372 \\
\hline \multicolumn{10}{|c|}{ PANEL II: UPGRADES } \\
\hline \multirow[b]{2}{*}{ Upgraded by } & \multicolumn{3}{|l|}{ S\&P } & \multicolumn{3}{|l|}{ Moody's } & \multicolumn{3}{|l|}{ Fitch } \\
\hline & (1) & (2) & (3) & (4) & (5) & (6) & (7) & (8) & (9) \\
\hline \multirow[t]{2}{*}{$S \& P$} & & & & $2.393^{* * *}$ & & $1.249^{* * *}$ & $2.685^{* * *}$ & & $2.170^{* * *}$ \\
\hline & & & & $(7.74)$ & & $(2.76)$ & (9.11) & & (5.98) \\
\hline \multirow[t]{2}{*}{ Moody's } & $2.190^{* * *}$ & & $1.082^{* * *}$ & & & & & $2.272^{* * *}$ & $0.996^{* *}$ \\
\hline & (7.04) & & (2.79) & & & & & $(7.15)$ & (2.49) \\
\hline \multirow[t]{2}{*}{ Fitch } & & $2.644^{* * *}$ & $2.033^{* * *}$ & & $2.527^{* * *}$ & $1.675^{* * *}$ & & & \\
\hline & & (7.87) & $(4.90)$ & & (7.98) & (3.65) & & & \\
\hline \multirow[t]{2}{*}{ CRA rating } & -0.0719 & 0.00570 & -0.00614 & -0.0224 & -0.0211 & -0.0211 & -0.0403 & $-0.100^{* *}$ & -0.0699 \\
\hline & $(-1.50)$ & $(0.11)$ & $(-0.11)$ & $(-0.41)$ & $(-0.38)$ & $(-0.38)$ & $(-0.79)$ & $(-2.07)$ & $(-1.32)$ \\
\hline Other controls & Yes & Yes & Yes & Yes & Yes & Yes & Yes & Yes & Yes \\
\hline Observations & 182633 & 182633 & 182633 & 186358 & 186358 & 186358 & 180794 & 180794 & 180794 \\
\hline
\end{tabular}

Note: This Table reports the estimated coefficients and t-statistic in parentheses of Eq. (1) where rating downgrade (Panel I) and upgrade (Panel II) hazard for each of the three rating agencies: S\&P, Moody's and Fitch. This was estimated using Cox Proportional Hazard modelling technique. The dataset consists of episodes of rating trend reversals presented in Table 2. The dependent variable is the time that elapsed (in days) between $1^{\text {st }}$ Jan 2000 (or a first day the rating was assigned if the sovereign was not rated before $1^{\text {st }}$ Jan 2000) of a sovereign by the observed CRA (S\&P Spec. 1-3; Moody's Spec. 4-6; Fitch Spec. 7-9) and the first downgrade (upgrade) of that sovereign identified as a trend reversal episode. Downgraded (Upgraded) by S\&P, Moody's and Fitch are dummy variables equal to 1 from the day the CRA downgrades (upgrades) the sovereign in the given episode, and 0 otherwise. CRA rating is the sovereign rating level expressed in 20-notch rating scale assigned on the $1^{\text {st }}$ Jan 2000 (or a first day the rating is assigned if the sovereign is not rated before $1^{\text {st }}$ Jan 2000 ) by the given CRA. Control variables are defined in the main text. Significance levels are: ${ }^{* * *} p<1 \%,{ }^{* *} p<5 \%,{ }^{*} p<10 \%$.

is influenced by Moody's and Fitch. To control for the sovereigns' characteristics that might affect their downgrade (upgrade) hazard, we include as controls the initial sovereign credit ratings (or ratings that prevail on $1^{\text {st }}$ January 2000 if the sovereigns have been rated prior to this date) and their economic fundamentals including GDP per capita and government budget balance (as percentage of GDP) reported in the years immediately preceding the rating actions. Our selection of economic controls is informed by CRAs sovereign rating methodologies (e.g., S\&P, 2017; Fitch 2020). We source the macroeconomic data directly from the World Bank's Worldwide Development Indicators. 
TABLE 5 Commercial mousetrap hypothesis - Eq. (2)

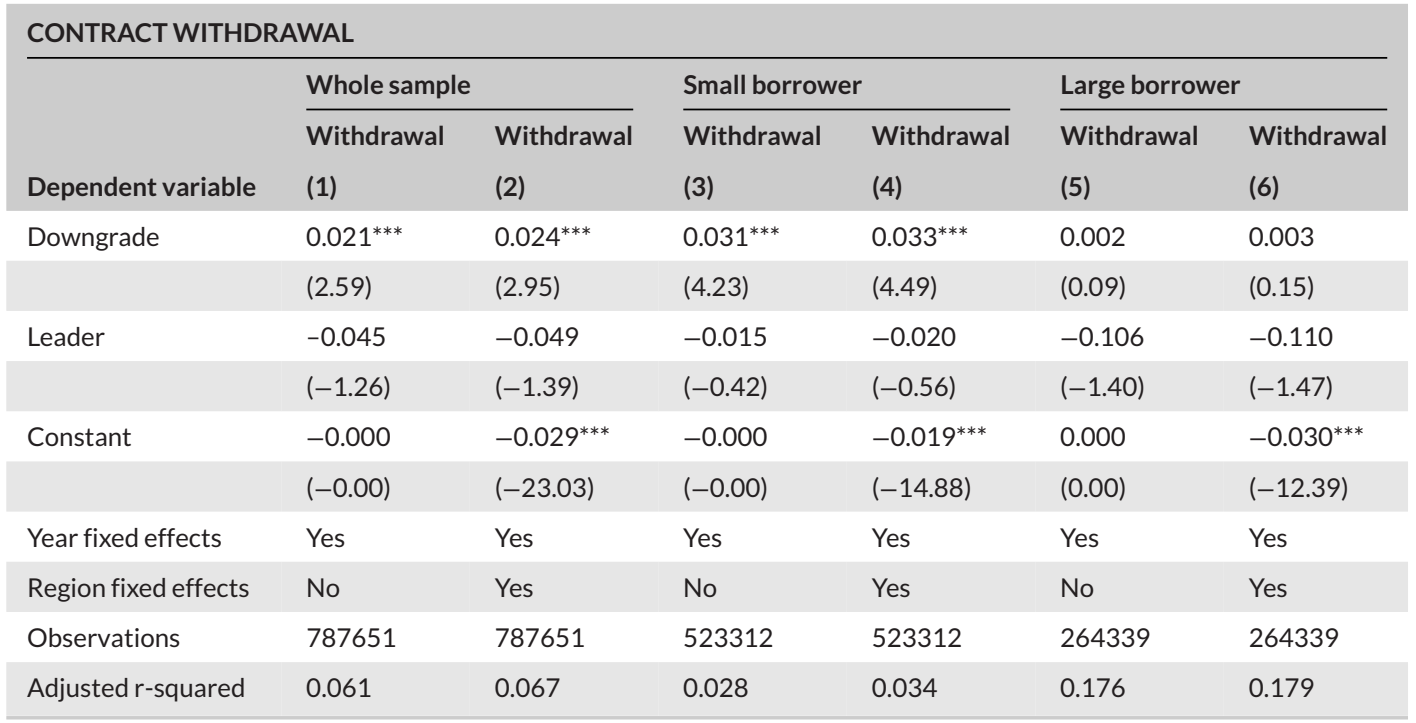

Note: This Table reports estimated coefficients and t-statistic in parentheses of Eq. (2) using OLS modelling approach (Section 4.2.1). The dataset consists of a panel of S\&P rated sovereigns between Jan 2000 and Feb 2019 (Whole sample). Small (large) borrower relates to a sovereign with less than (more than) $\$ 100$ billion of sovereign debt outstanding in 2018. Dependent variable is contract withdrawal dummy variable (this also consists of solicitation status switch from solicited to unsolicited). This variable is available throughout the sample period Jan 2000 -Feb 2019 .Significance levels are: ${ }^{* * *} p<1 \%,{ }^{* *} p<5 \%$, $* \mathrm{p}<10$.

TAB LE 6 Commercial mousetrap hypothesis - Eq. (2)- Regional breakdown

\begin{tabular}{|c|c|c|c|c|c|c|}
\hline \multirow[b]{2}{*}{ Dependent variable } & \multicolumn{2}{|l|}{ EMEA } & \multicolumn{2}{|l|}{ Americas } & \multicolumn{2}{|l|}{ Asia Pacific } \\
\hline & $\begin{array}{l}\text { Withdrawal } \\
\text { (1) }\end{array}$ & $\begin{array}{l}\text { Withdrawal } \\
\text { (2) }\end{array}$ & $\begin{array}{l}\text { Withdrawal } \\
\text { (1) }\end{array}$ & $\begin{array}{l}\text { Withdrawal } \\
\text { (2) }\end{array}$ & $\begin{array}{l}\text { Withdrawal } \\
\text { (1) }\end{array}$ & $\begin{array}{l}\text { Withdrawal } \\
\text { (2) }\end{array}$ \\
\hline \multirow[t]{2}{*}{ Downgrade } & $0.020^{*}$ & $0.020^{*}$ & $0.025^{* * *}$ & $0.025^{* * *}$ & -0.011 & -0.011 \\
\hline & $(1.67)$ & $(1.67)$ & (3.28) & (3.28) & $(-0.32)$ & $(-0.32)$ \\
\hline \multirow[t]{2}{*}{ Leader } & -0.049 & -0.049 & -0.046 & -0.046 & -0.013 & -0.013 \\
\hline & $(-1.09)$ & $(-1.09)$ & $(-0.87)$ & $(-0.87)$ & $(-0.08)$ & $(-0.08)$ \\
\hline \multirow[t]{2}{*}{ Constant } & 0.000 & 0.000 & -0.000 & -0.000 & 0.000 & 0.000 \\
\hline & $(0.00)$ & $(0.00)$ & $(-0.00)$ & $(-0.00)$ & $(0.00)$ & $(0.00)$ \\
\hline Year fixed effects & Yes & Yes & Yes & Yes & Yes & Yes \\
\hline Region fixed effects & No & Yes & No & Yes & No & Yes \\
\hline Observations & 456528 & 456528 & 190830 & 190830 & 140293 & 140293 \\
\hline Adjusted r-squared & 0.057 & 0.057 & 0.038 & 0.038 & 0.152 & 0.152 \\
\hline
\end{tabular}

Note: This Table reports estimated coefficients and t-statistic in parentheses of Eq. (2) using OLS modelling approach (Section 4.2.1). The dataset consists of a panel of S\&P rated sovereigns between Jan 2000 and Feb 2019. Regions according to World Bank definition include Europe, Middle East, Central Asia (EMEA), Americas, and Asia Pacific. The dependent variable is contract withdrawal dummy variable (this also consists of solicitation status switch from solicited to unsolicited). Spec. (2) yields the same results as Spec. (1) as regional dummies are dropped due to collinearity. Significance levels are: ${ }^{* * *} p<1 \%,{ }^{* *}$ $p<5 \%,{ }^{*} p<10$. 
TAB LE 7 Summary statistics of S\&P's relative sovereign rating coverage, market share and downgrade intensity

\begin{tabular}{|c|c|c|c|c|c|}
\hline Variables & $\mathbf{N}$ & Mean & $\begin{array}{l}\text { Standard } \\
\text { Deviation }\end{array}$ & Minimum & Maximum \\
\hline S\&P/Moody's coverage ratio & 51 & 1.01 & 0.11 & 0.87 & 1.26 \\
\hline S\&P/Fitch coverage ratio & 51 & 1.24 & 0.13 & 1.03 & 1.47 \\
\hline S\&P's region market share & 51 & 0.85 & 0.06 & 0.76 & 0.96 \\
\hline S\&P/Moody's coverage ratio - Americas & 17 & 0.95 & 0.05 & 0.87 & 1.00 \\
\hline S\&P/Moody's coverage ratio - Asia Pacific & 17 & 0.98 & 0.07 & 0.88 & 1.05 \\
\hline S\&P/Moody's coverage ratio - EMEA & 17 & 1.10 & 0.12 & 0.91 & 1.26 \\
\hline S\&P/Fitch coverage ratio - Americas & 17 & 1.37 & 0.06 & 1.24 & 1.47 \\
\hline S\&P/Fitch coverage ratio - Asia Pacific & 17 & 1.23 & 0.12 & 1.05 & 1.38 \\
\hline S\&P/Fitch coverage ratio - EMEA & 17 & 1.12 & 0.06 & 1.03 & 1.20 \\
\hline S\&P's region market share - Americas & 17 & 0.82 & 0.02 & 0.76 & 0.84 \\
\hline S\&P's region market share - Asia Pacific & 17 & 0.91 & 0.05 & 0.84 & 0.96 \\
\hline S\&P's region market share - EMEA & 17 & 0.82 & 0.03 & 0.77 & 0.86 \\
\hline S\&P's downgrade intensity & 612 & 0.51 & 1.05 & 0 & 9 \\
\hline S\&P's downgrade intensity - small borrowers & 612 & 0.37 & 0.84 & 0 & 7 \\
\hline S\&P's downgrade intensity - big borrowers & 612 & 0.14 & 0.43 & 0 & 5 \\
\hline S\&P's first-mover downgrade intensity & 612 & 0.06 & 0.28 & 0 & 4 \\
\hline S\&P's first-mover downgrade intensity - small borrowers & 612 & 0.06 & 0.27 & 0 & 4 \\
\hline S\&P's first-mover downgrade intensity - big borrowers & 612 & 0.03 & 0.17 & 0 & 2 \\
\hline
\end{tabular}

Note: This table summarises S\&P's annual region market shares, their ratios of sovereign rating coverage compared with Moody's and Fitch and S\&P's monthly downgrade intensity. The rating coverage ratios, market shares and downgrade intensity are explained in Section 4.2.2.

\subsection{The multivariate analysis of commercial trap hypothesis}

Although empirical investigations into the lead-lag relationship among global CRAs often cite S\&P as the most independent one in downgrading sovereigns (Alsakka and ap Gwilym, 2010, Hill and Faff, 2010, Chen et al., 2019), none of these studies look into the commercial impact of such downgrades on the CRAs making the downgrades, particularly the leader-CRA, in this case S\&P. Therefore, we fill this void in the literature, providing original insights into this issue. In order to answer the question of whether sovereign rating downgrades incur significant negative financial repercussions for the downgrading CRA, we examine the direct impact of S\&P's sovereign rating downgrades on the probability that rating contracts are cancelled by sovereign clients. Additionally, we test the impact of S\&P's downgrades on its relative sovereign rating coverage. Loss of rating contracts with sovereign clients does not only affect S\&P's financial results in the sovereign rating segment but also causes loss in rating revenues in non-sovereign asset classes. This is because there may be non-sovereign issuers in a jurisdiction where the sovereign cancels the contract that would discontinue their own rating contract, because their ratings are tied to the sovereign or because they are owned and controlled by the sovereign (such as state-owned enterprises, or some financial institutions). ${ }^{x x}$

We trawl through S\&P's press releases to identify the dates when sovereign clients cancelled contracts with this CRA. There are two possible signals of contracts being cancelled. First, S\&P withdraws and discontinues the ratings due to cancellation of contracts upon request of the sovereign issuer. Second, although contracts are cancelled, S\&P continues to keep the ratings on an unsolicited basis due to market interest in the sovereign clients' creditworthiness. 
TABLE 8 Commercial mousetrap hypothesis - Eq. (3)

\begin{tabular}{|c|c|c|c|c|c|c|}
\hline \multicolumn{7}{|l|}{ MARKET SHARE } \\
\hline \multirow[b]{2}{*}{ Dependent variable } & \multicolumn{6}{|c|}{ Whole sample } \\
\hline & $\begin{array}{l}\text { S\&P vs. } \\
\text { Moody's } \\
\text { (1) }\end{array}$ & $\begin{array}{l}\text { S\&P vs. } \\
\text { Moody's } \\
(2)\end{array}$ & $\begin{array}{l}\text { S\&P vs. } \\
\text { Fitch } \\
\text { (3) }\end{array}$ & $\begin{array}{l}\text { S\&P vs. } \\
\text { Fitch } \\
\text { (4) }\end{array}$ & $\begin{array}{l}\text { S\&P region } \\
\text { market share } \\
\text { (5) }\end{array}$ & $\begin{array}{l}\text { S\&P region } \\
\text { market share } \\
\text { (6) }\end{array}$ \\
\hline \multirow[t]{2}{*}{ Downgrade } & $-0.010^{* * *}$ & $-0.009^{* * *}$ & 0.005 & -0.002 & $-0.007^{* * *}$ & $-0.002^{* *}$ \\
\hline & $(-2.65)$ & $(-3.47)$ & $(1.02)$ & $(-1.08)$ & $(-4.17)$ & $(-2.01)$ \\
\hline \multirow[t]{2}{*}{ Leader } & 0.011 & -0.013 & $-0.044^{* *}$ & -0.006 & -0.009 & -0.003 \\
\hline & $(0.71)$ & $(-1.12)$ & $(-2.10)$ & $(-0.68)$ & $(-1.17)$ & $(-0.84)$ \\
\hline \multirow[t]{2}{*}{ Constant } & $0.993^{* * *}$ & $0.913^{* * *}$ & $1.222^{* * *}$ & $1.387^{* * *}$ & $0.825^{* * *}$ & $0.805^{* * *}$ \\
\hline & $(1.88)$ & $(2.30)$ & $(1.81)$ & (4.31) & (3.43) & $(5.89)$ \\
\hline Year fixed effects & Yes & Yes & Yes & Yes & Yes & Yes \\
\hline Region fixed effects & No & Yes & No & Yes & No & Yes \\
\hline Observations & 689065 & 689065 & 689065 & 689065 & 689065 & 689065 \\
\hline Adjusted r-squared & 0.381 & 0.694 & 0.153 & 0.830 & 0.246 & 0.786 \\
\hline
\end{tabular}

Note: This Table reports estimated coefficients and t-statistic in parentheses of Eq. (3) using OLS modelling approach (Section 4.2.2). The dataset consists of a panel of S\&P rated sovereigns between Jan 2000 and Feb 2019. Dependent variable S\&P vs. Moody's (S\&P vs. Fitch) is the ratio of S\&P's to Moody's (Fitch's) annual sovereign rating coverage in each of the three regions including EMEA, Americas and Asia Pacific. The dependent variable S\&P region market share refers to the S\&P's annual region market share defined by the number of sovereigns rated by S\&P as percentage of all sovereigns rated by any three global CRAs in a year. Significance levels are: ${ }^{* *} \mathrm{p}<1 \%,{ }^{* *} \mathrm{p}<5 \%,{ }^{*} \mathrm{p}<10$.

We rely on three reports by S\&P released on $24^{\text {th }}$ February 2011 in which S\&P announced unsolicited ratings for fourteen countries worldwide, including Belgium, France, Germany, Italy, Netherlands, Switzerland, United Kingdom, Australia, Cambodia, India, Japan, Singapore, Taiwan and the United States (S\&P, 2011a, S\&P, 2011b, S\&P, 2011c). There are four more similar announcements since 2011, including Turkey in 2013, Sweden and Portugal in 2014, and Saudi Arabia in 2015. Ratings for Gabon, Tunisia, Guernsey and the Isle of Man were withdrawn by S\&P rather than surveyed on an unsolicited basis. Guernsey was later reinstated upon signing of a new rating agreement with S\&P. The data availability of solicitation status for the other two biggest CRAs (Moody's and Fitch) is not widely available and the European CRA Regulator (ESMA) reports only the most recent solicitation status. Therefore, it is more difficult to identify similar losses of sovereign contracts for these CRAs.

Our multivariate analysis utilizing the information on solicitation status and rating withdrawals is based on a linear probability regression model specified as follows:

$$
\text { Withdrawal }_{i, t}=\alpha+\beta_{1} \text { Downgrade }_{i, t-3}+\beta_{2} \text { Leader }_{i, t-3}+Y_{t}+R_{j}+\varepsilon_{i t}
$$

Where the dependent variable Withdrawal $_{i, t}$ is a binary variable taking value one in year $t$ if S\&P already withdrew a sovereign rating or switched it from solicited to unsolicited status. Downgrade $e_{i, t-3}$ is a dummy variable taking value of unity if S\&P downgrades sovereign $i$ in year $t-3$, zero otherwise; and Leader $_{i, t-3}$ is a dummy for S\&P being the first mover in an episode of negative credit trend reversal in sovereign i. $\varepsilon_{i t}$ is an i.i.d random disturbance term. To control for the time-variant global market factors, we add a full set of year dummies $Y_{t}$ as controls. We also control for the regionspecific factors by adding a full set of region dummies $\boldsymbol{R}_{\mathbf{j}}$. We classify sovereigns into one of three regions, including EMEA (European, Middle East, Africa and Central Asia), Americas (North America, Latin America and the Caribbean) 
TAB LE 9 Commercial mousetrap hypothesis- Eq. (3) - Small Borrowers

\begin{tabular}{|c|c|c|c|c|c|c|}
\hline \multicolumn{7}{|l|}{ MARKET SHARE } \\
\hline \multirow[b]{3}{*}{ Dependent variable } & \multicolumn{6}{|c|}{ Small Borrower } \\
\hline & $\begin{array}{l}\text { S\&P vs. } \\
\text { Moody's }\end{array}$ & $\begin{array}{l}\text { S\&P vs. } \\
\text { Moody's }\end{array}$ & $\begin{array}{l}\text { S\&P vs. } \\
\text { Fitch }\end{array}$ & $\begin{array}{l}\text { S\&P vs. } \\
\text { Fitch }\end{array}$ & $\begin{array}{l}\text { S\&P region } \\
\text { market share }\end{array}$ & $\begin{array}{l}\text { S\&P region } \\
\text { market share }\end{array}$ \\
\hline & (1) & (2) & (3) & (4) & (5) & (6) \\
\hline \multirow[t]{2}{*}{ Downgrade } & $-0.011^{* * *}$ & $-0.009^{* * *}$ & 0.003 & $-0.004^{*}$ & $-0.005^{* * *}$ & $-0.002^{* *}$ \\
\hline & $(-2.59)$ & $(-3.00)$ & (0.58) & $(-1.87)$ & $(-3.37)$ & $(-2.02)$ \\
\hline \multirow[t]{2}{*}{ Leader } & 0.002 & -0.021 & $-0.059^{* *}$ & -0.018 & -0.009 & -0.007 \\
\hline & (0.09) & $(-1.43)$ & $(-2.19)$ & $(-1.64)$ & $(-1.18)$ & $(-1.52)$ \\
\hline \multirow[t]{2}{*}{ Constant } & $0.986^{* * *}$ & $0.908^{* * *}$ & $1.232^{* * *}$ & $1.390^{* * *}$ & $0.815^{* * *}$ & $0.804^{* * *}$ \\
\hline & $(1.36)$ & $(1.65)$ & $(1.30)$ & (3.41) & $(2.96)$ & $(4.62)$ \\
\hline Year fixed effects & Yes & Yes & Yes & Yes & Yes & Yes \\
\hline Region fixed effects & No & Yes & No & Yes & No & Yes \\
\hline Observations & 454470 & 454470 & 454470 & 454470 & 454470 & 454470 \\
\hline Adjusted r-squared & 0.365 & 0.662 & 0.119 & 0.849 & 0.280 & 0.733 \\
\hline
\end{tabular}

Note: This Table reports estimated coefficients and t-statistic in parentheses of Eq. (3) using OLS modelling approach (Section 4.2.2). The dataset consists of a panel of S\&P rated sovereigns between Jan 2000 and Feb 2019. Small borrower relates to a sovereign with less than $\$ 100$ billion of sovereign debt outstanding in 2018. Dependent variable S\&P vs. Moody's (S\&P vs. Fitch) is the ratio of S\&P's to Moody's (Fitch's) annual sovereign rating coverage in each of the three regions including EMEA, Americas and Asia Pacific. The dependent variable S\&P region market share refers to the S\&P's annual region market share defined by the number of sovereigns rated by S\&P as percentage of all sovereigns rated by any three global CRAs in a year. Significance levels are: ${ }^{* * *} p<1 \%,{ }^{* *} p<5 \%,{ }^{*} p<10$. Significance levels are: ${ }^{* * *} p<1 \%,{ }^{* *} p<5 \%,{ }^{*} p<10$.

and Asia Pacific. If downgrading a sovereign and being the first CRA to downgrade a sovereign increase the likelihood of losing customers, we expect the coefficients on Downgrade $e_{i, t-3}$ and Leader $_{i, t-3}$ to be positive and significant.

New sovereign clients are typically advised by sell-side ratings advisors. Since advisors want the best ratings for their clients, they may advise governments to stay away from the most conservative CRA, i.e. S\&P. Given the commercial trap hypothesis holds, one would expect that over time the coverage of S\&P in terms of sovereigns covered globally and across regions would gradually decline. For example, if the ratio of rated sovereigns by S\&P would have been $1.2 x$ those of Moody's in 2000, that ratio might fall to 1.1 for example, as new customers eschew S\&P upon advice of their financial advisors from investment banks. Therefore, the penalty for the first-mover can be measured by the changes in their relative sovereign rating coverage following the downgrades.

We test the above prediction empirically with a multivariate linear regression model, which is specified as follows:

$$
\text { RSC }_{j, t}=\alpha+\beta_{1} \text { Downgrade }_{i, t-3}+\beta_{2} \text { Leader }_{i, t-3}+Y_{t}+R_{j}+\varepsilon_{i t}
$$

Where $R S C_{j, t}$ measures S\&P's relative sovereign rating coverage for region $j$ in year $t$, and the RHS variables remain the same as in Eq. (2). Firstly, we define $R S C_{j, t}$ as the ratio of S\&P sovereign rating coverage to Moody's (Fitch's) sovereign rating coverage calculated for each of the three geographical regions, i.e. EMEA, Americas and Asia Pacific, in a given year. Such a ratio indicates S\&P's market power relative to their major rivals. Secondly, we define $R S C_{j, t}$ by the proportion of sovereigns rated by $S \& P$ in a year to the total number of sovereigns rated by any three global CRAs in the same year. ${ }^{x x i}$ Our second definition of $R S C_{j, t}$ follows Becker and Milbourn (2011) in calculating S\&P's sovereign rating market share. $R S C_{j, t}$ is referred to as S\&P's annual region market share. Here we remove the data restriction that sovereigns are rated by all the three global CRAs, hence the rating coverage and market share are calculated on the entire population of sovereigns rated by each global CRA. 
TAB LE 10 Commercial mousetrap hypothesis- - Eq. (3) - Large Borrowers

\begin{tabular}{lllllll} 
MARKET SHARE & \multicolumn{1}{l}{$l$} & & \\
\hline & \multicolumn{1}{l}{ Large Borrower } \\
\cline { 2 - 6 } & $\begin{array}{l}\text { S\&P vs. } \\
\text { Moody's }\end{array}$ & $\begin{array}{l}\text { S\&P vs. } \\
\text { Moody's }\end{array}$ & $\begin{array}{l}\text { S\&P vs. } \\
\text { Fitch }\end{array}$ & $\begin{array}{l}\text { S\&P vs. } \\
\text { Fitch }\end{array}$ & $\begin{array}{l}\text { S\&P region } \\
\text { market share }\end{array}$ & $\begin{array}{l}\text { S\&P region } \\
\text { market share }\end{array}$ \\
Dependent variable & $(1)$ & $(2)$ & $(3)$ & $(4)$ & $(5)$ & $(6)$ \\
\hline Downgrade & -0.008 & $-0.009^{*}$ & 0.009 & 0.005 & $-0.008^{* *}$ & -0.001 \\
\hline Leader & $(-0.98)$ & $(-1.80)$ & $(1.02)$ & $(1.09)$ & $(-1.96)$ & $(-0.65)$ \\
\hline Constant & 0.031 & 0.004 & -0.014 & 0.015 & -0.010 & 0.004 \\
\hline Year fixed effects & $(1.14)$ & $(0.23)$ & $(-0.45)$ & $(0.93)$ & $(-0.68)$ & $(0.64)$ \\
\hline Region fixed effects & $1.002^{* * *}$ & $0.914^{* * *}$ & $1.210^{* * *}$ & $1.380^{* * *}$ & $0.839^{* * *}$ & $0.804^{* * *}$ \\
\hline Observations & $(1.32)$ & $(1.65)$ & $(1.35)$ & $(2.67)$ & $(2.00)$ & $(3.71)$ \\
\hline Adjusted r-squared & Yes & Yes & Yes & Yes & Yes & Yes \\
\hline
\end{tabular}

Note: This Table reports estimated coefficients and t-statistic in parentheses of Eq. (3) using OLS modelling approach (Section 4.2.2). The dataset consists of a panel of S\&P rated sovereigns between Jan 2000 and Feb 2019. Large borrower relates to a sovereign with more than $\$ 100$ billion of sovereign debt outstanding in 2018 . Dependent variable S\&P vs. Moody's (S\&P vs. Fitch) is the ratio of S\&P's to Moody's (Fitch's) annual sovereign rating coverage in each of the three regions including EMEA, Americas and Asia Pacific. The dependent variable S\&P region market share refers to the S\&P's annual region market share defined by the number of sovereigns rated by S\&P as percentage of all sovereigns rated by any three global CRAs in a year. Significance levels are: ${ }^{* * *} p<1 \%,{ }^{* *} p<5 \%,{ }^{*} p<10$.

With both definitions, $R S C_{j, t}$ varies by region and year. In order to control for the time-variant market factors that affect S\&P's relative sovereign rating coverage, we add a full set of year dummies $Y_{t}$ as controls. We also control for the region-specific time-invariant factors by adding a full set of region dummies. If sovereign rating downgrades reduce S\&P's sovereign rating coverage relative to their rival CRAs as well as their sovereign rating market share, particularly when they downgrade the sovereign before Moody's and Fitch do so as well, we expect to observe negative and significant coefficients on Downgrade $e_{i, t-3}$ and Leader $_{i, t-3}$.

Eq. (3) investigates S\&P's downgrade at a single country level. It can be argued that it is S\&P's sovereign rating downgrade intensity that causes the decline in S\&P's relative sovereign rating coverage and market share. This is because sovereign clients observe the frequency of downgrades in a particular region to identify the most downgrade-prone CRA. Then we should expect that sovereign rating downgrade intensity affects S\&P's future sovereign rating coverage and sovereign rating market share in the similar manner to a downgrade on a single country. To test this prediction, we estimate a linear regression model specified as follows:

$$
\text { RSC }_{j, t}=\alpha+\beta_{1} \text { DownIntensity }_{j, t-k}+\beta_{2} \text { FMIntensity }_{j, t-k}+Y_{t}+R_{j}+\varepsilon_{j t}
$$

The subscript $j$ stands for one of the three regions in our sample, including EMEA, Americas and Asia Pacific. Subscript $t$ represents the month. Each region-month observation constitutes one data point in this model, and there are 612 such observations in total. DownIntensity is the number of S\&P's downgrades and FMIntensity is the number of S\&P's first-mover downgrades. We count the downgrades for each region in each month, disregarding the magnitudes of the downgrades. First-mover downgrades are the sovereign downgrades where S\&P is the first-mover in an episode of negative credit trend reversal identified in Section 3.1. Similar to Eq. (3), $R S C_{j, t}$ is S\&P's annual region sovereign rating market share and sovereign rating coverage ratios (relative to Moody's or Fitch). The time-lag between the 
TAB LE 11 Commercial mousetrap hypothesis - Eq. (4)

\begin{tabular}{|c|c|c|c|c|c|c|}
\hline \multirow[b]{2}{*}{ Dependent variable } & \multicolumn{6}{|c|}{ Whole sample } \\
\hline & $\begin{array}{l}\text { S\&P vs. } \\
\text { Moody's } \\
\text { (1) }\end{array}$ & $\begin{array}{l}\text { S\&P vs. } \\
\text { Moody's } \\
\text { (2) }\end{array}$ & $\begin{array}{l}\text { S\&P vs. } \\
\text { Fitch } \\
\text { (3) }\end{array}$ & $\begin{array}{l}\text { S\&P vs. } \\
\text { Fitch } \\
\text { (4) }\end{array}$ & $\begin{array}{l}\text { S\&P region } \\
\text { market share } \\
\text { (5) }\end{array}$ & $\begin{array}{l}\text { S\&P region } \\
\text { market share } \\
\text { (6) }\end{array}$ \\
\hline \multirow[t]{2}{*}{ Downgrade Intensity } & 0.006 & $-0.012^{* * *}$ & $-0.016^{* * *}$ & -0.001 & $-0.013^{* * *}$ & -0.002 \\
\hline & $(1.44)$ & $(-3.84)$ & $(-3.00)$ & $(-0.05)$ & $(-5.41)$ & $(-1.29)$ \\
\hline \multirow{2}{*}{$\begin{array}{l}\text { First mover Downgrade } \\
\text { Intensity }\end{array}$} & 0.008 & -0.006 & -0.030 & -0.007 & -0.001 & -0.002 \\
\hline & $(0.50)$ & $(-0.57)$ & $(-1.49)$ & $(-0.64)$ & $(-0.02)$ & $(-0.51)$ \\
\hline \multirow[t]{2}{*}{ Constant } & $0.976^{* * *}$ & $0.917^{* * *}$ & $1.283^{* * *}$ & $1.406^{* * *}$ & $0.835^{* * *}$ & $0.799^{* * *}$ \\
\hline & (62.11) & (80.53) & (64.78) & $(125.11)$ & (98.16) & (171.40) \\
\hline Year fixed effects & Yes & Yes & Yes & Yes & Yes & Yes \\
\hline Region fixed effects & No & Yes & No & Yes & No & Yes \\
\hline Observations & 612 & 612 & 612 & 612 & 612 & 612 \\
\hline Adjusted r-squared & 0.204 & 0.625 & 0.169 & 0.760 & 0.198 & 0.784 \\
\hline
\end{tabular}

Note: This Table reports estimated coefficients and t-statistic in parentheses of Eq. (4) using OLS modelling approach (Section 4.2.2). The dataset consists of a panel of S\&P rated sovereigns between Jan 2000 and Feb 2019. Dependent variable S\&P vs. Moody's (S\&P vs. Fitch) is the ratio of S\&P's to Moody's (Fitch's) annual sovereign rating coverage in each of the three regions including EMEA, Americas and Asia Pacific. The dependent variable S\&P region market share refers to the S\&P's annual region market share defined by the number of sovereigns rated by S\&P as percentage of all sovereigns rated by any three global CRAs in a year. Significance levels are: ${ }^{* *} p<1 \%,{ }^{* *} p<5 \%,{ }^{*} p<10$.

region-month observation of downgrade (and first-mover downgrade) intensity and $R S C_{j, t}$ is three years ( $\mathrm{k}=36$ months). If our prediction is supported by the data, we expect to find negative and significant coefficients on DownIntensity and FMIntensity.

\section{4 | EMPIRICAL RESULTS}

\section{1 | Lead-lag relationship in sovereign rating changes}

In this section, we examine empirically the lead-lag relationship in sovereign ratings between three global CRAs, including S\&P, Moody's and Fitch. The primary purpose of this section is to unveil the first-mover CRA. Our examination is conducted on 120 episodes of sovereign credit trend reversal, consisting of a univariate analysis of the Leadership Index and a multivariate analysis with the semi-parametric Cox proportional hazard model. In general, both analyses highlight S\&P to be the first-mover CRA, particularly when it comes to downgrades.

\subsection{1 | Leadership index}

In Table 1, we report all 120 episodes of credit trend reversal of both types in our sample period. We supplement the data with a Leadership Index and report the z-statistics for a Wilcoxon matched-pair sign rank test on the equivalence in the rank between S\&P and their rival CRAs, namely Moody's and Fitch at the bottom rows of each panel. We devise 
TAB LE 12 Commercial mousetrap hypothesis- Eq. (4) - Small Borrowers

\begin{tabular}{|c|c|c|c|c|c|c|}
\hline \multicolumn{7}{|c|}{ MARKET SHARE: DOWNGRADES INTENSITY } \\
\hline \multirow[b]{2}{*}{ Dependent variable } & \multicolumn{6}{|c|}{ Small Borrower } \\
\hline & $\begin{array}{l}\text { S\&P vs. } \\
\text { Moody's } \\
\text { (1) }\end{array}$ & $\begin{array}{l}\text { S\&P vs. } \\
\text { Moody's } \\
\text { (2) }\end{array}$ & $\begin{array}{l}\text { S\&P vs. } \\
\text { Fitch } \\
\text { (3) }\end{array}$ & $\begin{array}{l}\text { S\&P vs. } \\
\text { Fitch } \\
\text { (4) }\end{array}$ & $\begin{array}{l}\text { S\&P region } \\
\text { market share } \\
\text { (5) }\end{array}$ & $\begin{array}{l}\text { S\&P region } \\
\text { market share } \\
\text { (6) }\end{array}$ \\
\hline \multirow[t]{2}{*}{ Downgrade Intensity } & 0.009 & $-0.014^{* * *}$ & $-0.022^{* * *}$ & -0.002 & $-0.016^{* * *}$ & -0.002 \\
\hline & $(1.56)$ & $(-3.67)$ & $(-3.26)$ & $(-0.61)$ & $(-5.47)$ & $(-1.11)$ \\
\hline \multirow{2}{*}{$\begin{array}{l}\text { First mover } \\
\text { Downgrade } \\
\text { Intensity }\end{array}$} & -0.000 & -0.004 & -0.008 & -0.002 & -0.002 & -0.003 \\
\hline & $(-0.01)$ & $(-0.31)$ & $(-0.39)$ & $(-0.14)$ & $(-0.19)$ & $(-0.67)$ \\
\hline \multirow[t]{2}{*}{ Constant } & $0.976^{* * *}$ & $0.917^{* * *}$ & $1.281^{* * *}$ & $1.406^{* * *}$ & $0.835^{* * *}$ & $0.799^{* * *}$ \\
\hline & $(62.18)$ & (80.33) & $(64.49)$ & $(125.14)$ & (98.38) & $(171.41)$ \\
\hline Year fixed effects & Yes & Yes & Yes & Yes & Yes & Yes \\
\hline Region fixed effects & No & Yes & No & Yes & No & Yes \\
\hline Observations & 612 & 612 & 612 & 612 & 612 & 612 \\
\hline Adjusted r-squared & 0.203 & 0.623 & 0.163 & 0.760 & 0.201 & 0.784 \\
\hline
\end{tabular}

Note: This Table reports estimated coefficients and t-statistic in parentheses of Eq. (4) using OLS modelling approach (Section 4.2.2). The dataset consists of a panel of S\&P rated sovereigns between Jan 2000 and Feb 2019. Small borrower relates to a sovereign with less than $\$ 100$ billion of sovereign debt outstanding in 2018. Dependent variable S\&P vs. Moody's (S\&P vs. Fitch) is the ratio of S\&P's to Moody's (Fitch's) annual sovereign rating coverage in each of the three regions including EMEA, Americas and Asia Pacific. The dependent variable S\&P region market share refers to the S\&P's annual region market share defined by the number of sovereigns rated by S\&P as percentage of all sovereigns rated by any three global CRAs in a year. Significance levels are: ${ }^{* *} p<1 \%,{ }^{* *} p<5 \%,{ }^{*} p<10$. Significance levels are: ${ }^{* * *} p<1 \%,{ }^{* *} p<5 \%,{ }^{*} p<10$.

the comprehensive index to quantify the relative timeliness of a CRA in spotting the changes in the credit trend of a sovereign. In particular, the index is specified as follows:

$$
\text { LeadIndex }_{i}=\sum_{r=1}^{3} p_{r} \times r_{i}
$$

Where LeadIndex $i$ is the Leadership Index of CRA $i, r_{i}$ is the rank of CRA $i$ in an episode, and $p_{r}$ is the percentage of the times CRA $i$ gets the rank $r . r_{i}$ takes value 1 if CRA is the first-mover in a credit trend reversal episode, value 2 if CRA is the second-mover and value 3 if CRA is the third-mover. The Leadership Index indicates the sample average mean rank of a CRA. We also distinguish a CRA's Leadership Index in upgrade episodes from their Leadership index in downgrade episodes.

In theory, the LeadIndex $x_{i}$ takes any value in the continuous range between one and three. A high value of the index indicates a propensity to be the follower in an episode of sovereign credit trend reversal, whereas a low value would imply a propensity to the leader or first-mover. In the first most extreme case, CRA $i$ leads $100 \%$ of the time, their Leadership Index is one. In the second most extreme case, CRA $i$ is the last-mover in all episodes, hence their Leadership Index takes value of three. If all the three CRAs are equally likely to be the first-mover, i.e. there is no systematic difference in the timeliness of rating actions across the three CRAs, the Leadership Index for each CRA would be 2.

Hill and Faff (2010) employ the leader-follower ratio (LFR) initiated by Cooper et al. (2001) to examine the leadlag relationship between S\&P, Moody's and Fitch. Their LFR is the ratio of the time from the preceding rating action by another CRA to the time to the succeeding rating action by another CRA. Our index differs from theirs in that our 
TAB LE 13 Commercial mousetrap hypothesis- Eq. (4) - Large Borrowers

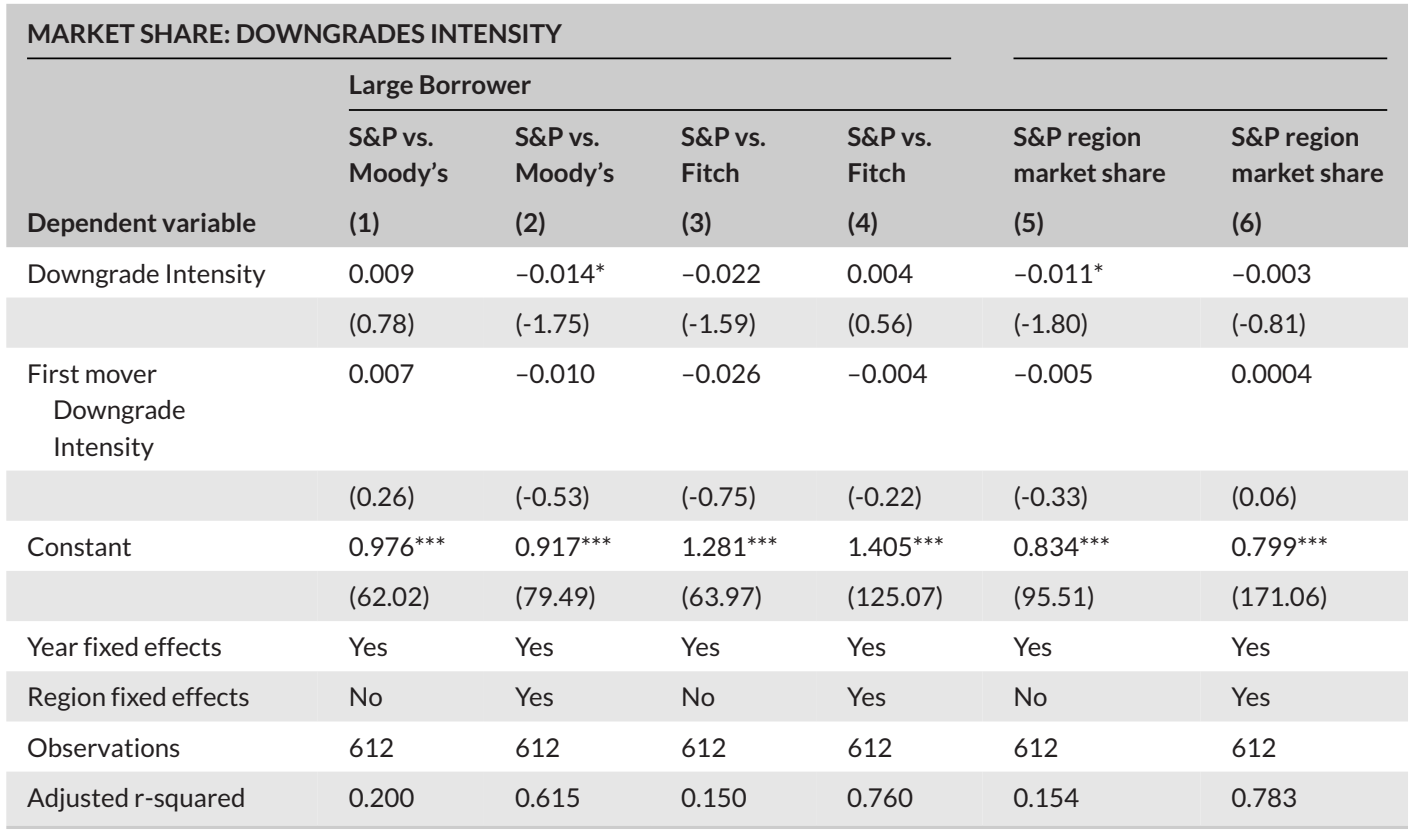

Note: This Table reports estimated coefficients and t-statistic in parentheses of Eq. (4) using OLS modelling approach (Section 4.2.2). The dataset consists of a panel of S\&P rated sovereigns between Jan 2000 and Feb 2019. Large borrower relates to a sovereign with more than $\$ 100$ billion of sovereign debt outstanding in 2018 . Dependent variable S\&P vs. Moody's (S\&P vs. Fitch) is the ratio of S\&P's to Moody's (Fitch's) annual sovereign rating coverage in each of the three regions including EMEA, Americas and Asia Pacific. The dependent variable S\&P region market share refers to the S\&P's annual region market share defined by the number of sovereigns rated by S\&P as percentage of all sovereigns rated by any three global CRAs in a year. Significance levels are: ${ }^{* * *} p<1 \%,{ }^{* *} p<5 \%,{ }^{*} p<10$.

index points directly to the rank of a CRA in an episode of triple rating downgrades (upgrades) within a 5 year window and the rank is specified under our rigorous identification procedure mentioned earlier.

Consistent with the figures, Table 1 shows a clear trend for S\&P to lead the sovereign rating market. Their Leadership Index calculated on 120 episodes of credit trend reversal is 1.71, which is lower than both Moody's (2.16) and Fitch (2.13). The Leadership Index of S\&P is 1.51 and 1.88 for downgrade episodes and upgrade episodes, respectively. Both values point to S\&P as the first-mover for both directions in the changes of sovereign credit trends. The Wilcoxon sign-rank tests show that S\&P's leadership is more pronounced in downgrade episodes than in upgrade episodes. The evidence for S\&P's leadership is strongest in Europe \& Central Asia, Middle East and Africa (EMEA) and Americas. S\&P's relative position is least distinct in Asia Pacific for both positive and negative changes in sovereign credit quality (upgrade episodes and downgrade episodes). In Asia Pacific we find a leading role played by Moody's (Table 1, Panel II). Nevertheless, the z-statistic fails to reject the null that Moody's rank is indistinguishable from S\&P's.

To examine the time variation in the timeliness of rating actions across the three leading CRAs, we split the episodes into four subperiods: 2000-2004, 2005-2009, 2010-2014, and 2015-2019 and recalculate the Leadership Index for each CRA across 120 episodes, 55 downgrade episodes and 65 upgrade episodes (Table 1, Panel III). In contrast to Güttler and Wahrenburg (2007) who highlight the propensity for Moody's to lead S\&P in detecting corporate failure, our data show that S\&P's leadership in spotting negative sovereign credit quality persists over time. S\&P's leadership role intensifies over the years, especially in the period 2005-2009 and the more recent period 2015-2018. During the subperiod 2010-2014, there is a switch in the leadership of downgrade trends from S\&P to Moody's. S\&P's downgrades are slightly less timely than Moody's downgrades. Nevertheless, the difference in timeliness of rating downgrades between Moody's and S\&P during this period is not statistically significant. When there is an improvement in 
sovereign credit strength, S\&P moves first in half the full sample period. In the subperiods 2000-2004 and 2010-2014, Fitch tends to upgrade slightly faster than S\&P and Moody's, hence becomes the first-mover on average during those periods. However, the differences in the rank between Fitch and S\&P are not significantly different from zero.

The timeliness in detecting reversals of sovereign credit trend is valuable to investors, particularly when the sovereigns concerned are frequent borrowers on the capital market, i.e. they have a large amount of sovereign marketable debt outstanding. In Panel IV of Table 1, we segregate episodes concerning large sovereign borrowers from those concerning small borrowers. We define the large borrowers as those having at least $\$ 100$ billion of sovereign debt outstanding in 2018. We source the data on sovereign debt from S\&P's report "Sovereign debt 2019: Global borrowing to increase by $3.2 \%$ to US $\$ 7.8$ trillion. February 2019" (S\&P, 2019c). Out of 120 episodes of credit trend reversal, there are 41 episodes concerning large sovereign borrowers. S\&P moves first and is followed by Moody's and Fitch. S\&P's leadership is mostly driven by their tendency to downgrade faster than Moody's and Fitch when sovereign creditworthiness deteriorates. As far as the small sovereign borrowers are concerned, S\&P's leadership role is even more pronounced.

In Table 1, we report the results based on credit trend reversals which are defined within five years. To see the full list of the episodes, refer to Appendix Table A3. To examine the robustness of the results, we re-define the episodes within various windows ranging from one year to five years. Our results are displayed in Table 2 . For brevity, we only report the Leadership Index which indicates the average rank of each CRA across five different time windows between one and five years. Across all the five windows, S\&P demonstrates the least dependence among the three leading CRAs, especially with regards to trends of deterioration in sovereign credit quality (downgrades). Our earlier findings concerning S\&P's leadership in EMEA and Americas continue to hold at time windows shorter than five years. There is also little heterogeneity in the time evolution of the relative timeliness of rating actions by three CRAs across five different time windows. In summary, the evidence in favour of S\&P as the first-mover for both upgrading and downgrading trends remains robust.

Thus far our analyses cover episodes of reversal of credit trends, hence the rating levels associated with the rating actions in the episodes are not taken into consideration, i.e. it is only the direction of the rating action that matters. Nevertheless, it is believed that rating actions that cross the investment grade-speculative boundary (between BBB/Baa3 and BB/Ba1), have significant implications for investors' trading decisions. A downgrade that brings a sovereign from investment grade to speculative status (a so-called "fallen angel") can trigger forced sell off on the part of institutional investors or instigate certain contractual obligations under the debt covenants. On the other hand, an upgrade that lifts a sovereign from speculative status to investment grade ("rising star") increases the sovereign's investor base since many large institutional investors are allowed to hold only debt instruments with investment grade ratings. Given the importance of rating actions that cross the investment grade-speculative boundary, we investigate the relative timeliness of the three leading CRAs in respect of taking such actions (Table 3). We identify rating actions that cross the divide as either rising stars or fallen angels and examine the lead-lag relationship between the three main CRAs for such cases. There are 15 episodes associated with rising stars and 10 episodes associated with fallen angels in our sample (See Appendix Table A4). The leader in upgrading sovereigns to investment grade is Fitch. The countries affected come from a mix of three geographical regions, EMEA, Americas and Asia Pacific. Fitch tends to move first in $40 \%$ of the upgrades episodes, followed by S\&P (33\%) and Moody's (27\%). By contrast, S\&P leads the episodes of fallen angels. They are the first-mover $80 \%$ of the time, followed by Moody's (20\%). Fitch never leads in any episodes of fallen angels. A majority of the fallen angels are EMEAs countries, including Azerbaijan, Bahrain, Croatia, Cyprus, Greece, Hungary, Portugal, and Tunisia (for details on the individual episodes see Appendix Table A4).

To sum up, our preliminary results show that S\&P is the most independent CRA and typically fastest to respond to a deterioration in sovereign credit strength. Such prompt actions from the CRAs are welcomed by rating users whose investment decisions are informed by CRAs' credit opinions. In general, we find that S\&P's leadership persists over time and holds particularly strong for downgrades across the investment grade divide. They also lead in upgrade trends, though there are cases in which Fitch tends to act slightly faster, such as crossing the investment grade divide from below. 


\subsection{2 | The Cox proportional hazard model}

In Table 4, we report the estimation results of the Cox proportional hazard model. We summarise the results of downgrades in Panel I and upgrades in Panel II. Spec. (1), (2), and (3) in each Panel report the coefficient estimates for S\&P. Spec. (4), (5) and (6) report the estimates for Moody's. Finally, Spec. (7), (8) and (9) report the estimates for Fitch. Results show that rating actions by the three CRAs tend to herd toward each other. For example, in Panel I the hazard of downgrades from Moody's and Fitch increases steadily for sovereigns previously downgraded by S\&P. For example, downgrade intensity by Moody's conditional on S\&P's downgrade is 3.2, whereas downgrade intensity by Fitch conditional on S\&P is 3.9. This means that a downgrade by Moody's (Fitch) is 225\% (287\%) more likely if there was a downgrade by S\&P. We find a similar increase in the downgrade hazard from S\&P for sovereigns previously downgraded by Moody's and Fitch, but to a lesser extent by the latter CRA (downgrade intensity by S\&P conditional on Fitch is 3.0). The overall lower $t$-statistics for S\&P underline the slightly less pronounced herding behaviour of S\&P towards the competition than the other way around. In the joint effects model, we find that, other things equal, Moody's and Fitch are influenced more by S\&P than they influence each other (Spec. (6) and (9)). Considering the case of S\&P in Spec. (3), S\&P's downgrades are more strongly influenced by prior similar actions from Moody's than from Fitch. For example, downgrade intensity by S\&P conditional on Moody's is 2.7 whereas that of Fitch 1.6, i.e. a downgrade by S\&P is $173 \%$ (61\%) more likely if there was a prior downgrade by Moody's (Fitch) respectively. In terms of leadership, downgrades by S\&P undoubtedly influence downgrades by Moody's and Fitch to a greater extent than Moody's and Fitch influence each other. For instance, downgrade intensity by Moody's (Fitch) conditional on S\&P is 2.6 (3.4). On the other hand, Moody's intensity conditional on Fitch and vice versa is 1.6 and 1.7 respectively.

We find very similar results for upgrades in Panel II of Table 4. S\&P is the least dependent CRA and tends to influence its rivals' rating actions more than the other way around. In Spec. (3) and (6), Fitch tends to lead both S\&P and Moody's in upgrading trends. Nevertheless, when being a follower in an upgrade trend, the intensity of upgrades by Fitch is influenced by S\&P more than by Moody's (Spec. 9).

\section{2 | Commercial trap analyses}

The estimation results revealed by the Cox proportional hazard model discussed in the previous section substantiate the leadership role of S\&P in detecting changes in sovereign credit quality. Although they provide positive signals to rating users about the timeliness of S\&P's sovereign ratings compared with Moody's and Fitch, there remains an unanswered question about its implications for the first-mover CRA (S\&P). In this section, we provide an empirical investigation into this issue. The full results are reported in Tables 5-13.

\subsection{1 | Contract withdrawal}

Table 5 reports the estimation results of Eq. (2) implemented on the full sample of sovereign entities rated by S\&P as well as on two subsamples of small sovereign borrowers and large sovereign borrowers (rated by S\&P). Large sovereign borrowers are frequent issuers of debt instruments on the capital market. Among these large borrowers include United States, United Kingdom, Argentina, Australia, Brazil, Canada, China, Germany, India, Italy, Portugal, Russia, Spain, South Korea. We repeat these subsample analyses for three different geographical regions in Table 6, including EMEA, Americas and Asia Pacific.

Table 5 displays the coefficient estimates and their corresponding t-values in parentheses for Eq. (2). For each sample (the full sample and two subsamples), we run the Eq. (2) with year fixed effects in Spec.(1) and with year-region fixed effects in Spec. (2). Consistent with our prediction, a sovereign downgrade in a given year by the first-mover CRA (S\&P) 
results in a statistically significant increase in the likelihood of contracts being cancelled. The coefficient estimates on Downgrade take the correct signs for the full sample and for small sovereign borrowers, while turn insignificant for large borrowers. On average, one notch downgrade by S\&P increases the probability of contract withdrawal three years later by approximately $2.4 \%$ (Table 5 , Column 2). More contracts are lost due to cancellation by small sovereign borrowers than by large borrowers. Specifically, small borrowers are more likely to cancel contract within three years of a notch downgrade by $3.3 \%$ relative to a benchmark case of no rating change (Table 5 , Column 4). This estimate is strongly significant at $1 \%$ level. $^{\text {xxii }}$

In Table 6, we run Eq. (2) on three subsamples corresponding to three geographical regions in our dataset, including EMEA, Americas and Asia Pacific. Consistent with Table 1 in which S\&P leadership in downgrade episodes are more pronounced in EMEA and Americas, here we find that Downgrade is statistically significant with correct sign in EMEA (2.0\%) and Americas (2.5\%), but insignificant in Asia Pacific (1.1\%). The results reveal a heterogeneity in the impact of sovereign downgrades by S\&P's on their future loss of rating contracts. The commercial loss is most severe in countries where S\&P downgrades fastest. For both full sample analysis and the subsample analyses, we do not find specific evidence for Leader in case of contract withdrawals in Table 5 and Table 6. xxiii,xxiv

\subsection{2 | Market Share}

Turning to the examination of relative sovereign rating coverage and market share, we summarise S\&P's relative sovereign rating coverage, region market share and sovereign downgrade intensity in Table 7. Since RSC are forwarded by three years relative to the year of the rating observation, we lose the first three years of RSC (2000, 2001 and 2002). By the end of our sample period (January 2019), S\&P rated 127 countries. Throughout the 17-year period, on average, they rate about 120 countries per year on a global scale, more than both Moody's (116) and Fitch (101). S\&P's annual average market share across the three regions is $85 \%$ with a small standard deviation of only $6 \%{ }^{\text {xxv }}$ In comparison with both Moody's and Fitch, S\&P tends to have a larger pool of sovereign clients. The average ratio of S\&P's sovereign rating coverage to Moody's (Fitch) is greater than one. Looking into each region, we find S\&P dominates Fitch in all the three regions, while it becomes slightly less competitive than Moody's (smaller rating coverage) in the Americas and Asia Pacific. With regards to downgrade intensity, S\&P makes an average of 0.51 downgrade per region per month with a standard deviation of 1.05. Nevertheless, they can announce up to nine downgrades within a month. Small sovereign borrowers (0.37 downgrades per region per month) are more vulnerable to S\&P's downgrades than large borrowers (0.14 downgrades per region per month). They are also more prone to S\&P's first mover downgrades than large sovereign borrowers.

The estimation results of Eq. (3) are presented for the full sample of all sovereigns rated by S\&P in Table 8, the subsample of small and large borrowers in Tables 9 and 10 respectively. Table 8 reveals the empirical evidence for our prediction that S\&P's sovereign downgrades might endanger their market share. The first (second) two columns show the impact of downgrades on S\&P's sovereign rating coverage relative to Moody's (Fitch) three years later. The last two columns show the impact of S\&P's downgrades on their overall regional market shares. The results support our earlier prediction. For each one-notch downgrade, the overall annual regional market share declines by approximately $0.2 \%$ within three years after the downgrade occurs (Table 8 , Column 6). Considering an overall average number of sovereigns rated by any three global CRAs across three regions is 48 countries per region per year, S\&P's overall average market share of $85 \%$ is approximate to 41 countries per region per year. If we assume that sovereigns who terminate contracts with S\&P continue to solicit ratings from either Moody's or Fitch, then a loss of 0.2\% on S\&P's market share will be equivalent to a reduction of S\&P's average rating coverage from 41 sovereigns to 40.7 sovereigns ( $40.7=$ $(0.85-0.002) * 48)$.

Looking at the regressions on coverage ratios, we notice that the loss of market power relative to Moody's is much stronger than the loss to Fitch. For example, for a three-notch downgrade, S\&P's relative sovereign rating coverage declines by $2.7 \%\left(0.9 \%{ }^{*} 3\right)$ (Table 7 , Column 2$)$. This value is equivalent to a decline in S\&P's annual average relative 
sovereign rating coverage (compared with Moody's) across the three regions from 1.01 to 0.98 , and a loss of 1.05 sovereign customers. $x$ xvi

As regards the coverage ratio of S\&P to Moody's, we obtain strongly statistically significant coefficients on Downgrade in the subsample of small sovereign borrowers (Table 9), but small and weakly significant coefficients on Downgrade for large sovereign borrowers (Table 10). The results are consistent with Eq. (2) for contract withdrawal. For small borrowers, the loss of S\&P to Moody's is more pronounced than the loss of S\&P in relation to Fitch. Furthermore, small sovereign borrowers are more likely, than large sovereign borrowers, to cancel contracts as a result of the downgrades, thus adversely affecting S\&P's rating coverage relative to their major competitor (Moody's in particular).

In Tables 11-13, we present the estimation results of Eq. (4). In Table 11, we regress RSC on S\&P's downgrade intensity and first-mover downgrade intensity. We control the model for year fixed effects or region-year fixed effects. The sample consists of 612 region-month observations for which market shares and ratios of sovereign rating coverage are available. We run Eq. (4) on two versions of RSC. In columns (1-4), S\&P vs. Moody's (vs. Fitch), we measure RSC by the ratios of S\&P sovereign rating coverage to Moody's (Fitch's) sovereign rating coverage. In columns (5) and (6) named $S \& P$ region market share, $R S C$ is the S\&P's annual region market share. We notice a sharp increase in adjusted R-squared when the models are controlled by both region fixed effects and year fixed effects. With the inclusion of region dummies and year dummies, our model explains up to $78.4 \%$ of the variation in dependent variables. We find a statistically significant coefficient on Downlntensity in the case of S\&P's sovereign rating coverage relative to Moody's, but not in the case of S\&P's sovereign rating coverage relative to Fitch. The coefficient is strongly significant at $1 \%$ level and has the correct sign. For each additional downgrade made by S\&P in a region in a month, the ratio of S\&P to Moody's rating coverage drops by $1.2 \%$ in the following three years. We do not find similar evidence in the case of S\&P versus Fitch nor for S\&P's region market share sample. ${ }^{x x v i i}$ The result corroborates our earlier finding regarding the potential decline of S\&P's sovereign rating coverage relative to Moody's.

In Tables 12-13, we redefine the RHS variables and re-estimate Eq. (4). Specifically, we count S\&P's downgrades and S\&P's first-mover downgrades on small sovereign borrowers in Table 12 and on large sovereign borrowers in Table 13. We find strong evidence in favour of the commercial trap hypothesis in the case of small sovereign borrowers, and weaker evidence in the case of large sovereign borrowers. Both tables highlight the significant decrease in S\&P's sovereign rating coverage relative to Moody's.

In summary, our empirical evidence shows that the lead-lag relationship in sovereign credit ratings may impose a significant cost on the first mover, especially in the case of downgrades. Although the revealed results do not necessarily imply that there is a violation of the analytical independence principle in the production of sovereign credit ratings by issuer-pay CRAs, they highlight the important role of maintaining effective Chinese walls to prevent commercial motivations from interfering with analysts' sovereign credit assessments. ${ }^{\text {xxviii }}$ It stresses the importance that analysts are not subjected to any pressure, however subtly or informally conveyed, that could distort their incentives to shy away from a negative rating action.

\section{5 | CONCLUSION}

In this paper, we document that S\&P tends to be the first-mover in taking sovereign actions, particularly negative rating actions. We show that being a first-mover in downgrading sovereign ratings has negative commercial implications for the first-mover CRA (S\&P). Using a sample of 102 sovereigns rated by the three largest CRAs, including S\&P, Moody's and Fitch between January 2000 and January 2019, we show that the CRA making the timeliest downgrades receives a penalty in the form of contract withdrawals and decrease in relative sovereign rating coverage. Although S\&P is the quickest to respond to the new information released to the market, which enhances the relevance and timeliness for investors, it is penalised for its prompt actions by sovereign clients who might decide to cancel their business with S\&P following a downgrade. 
Our identification strategy relies on observing the direction of the rating changes (trend reversals) rather than their intensity, which enables us to identify which CRA is the quickest to incorporate the new information from the market into sovereign ratings before it becomes a consensus view.

Using the Cox proportional hazard model, we establish that S\&P is the first-mover in both sovereign rating upgrades and sovereign rating downgrades. Furthermore, we find that the propensity for S\&P to lose contracts rises by $2.4 \%$ with each one-notch downgrade announced by them. The more regular the downgrades occur, the more likely it is that S\&P's sovereign rating coverage relative to their major rival CRA (Moody's) would decline, hence adversely affecting S\&P's competitiveness. There is a potential trade-off for analysts to release timely downgrades, on the one hand, and to minimise perceived threats to their personal job security on the other, if the rating action jeopardises sovereign rating contracts. Considering on top of that the disproportional importance of sovereign ratings to the rest of the economy, special attention needs to be given to protecting the independence of sovereign analysts. Our results should be of interest of CRAs' own compliance departments, but also regulators, policymakers and investors, who are the ultimate users of sovereign ratings.

\section{ORCID}

Patrycja Klusak (D) https://orcid.org/0000-0001-5851-2461

\section{Notes}

' It is possible to recall recent rating actions by Moody's on 57 UK sub-sovereign entities and 39 special purpose vehicles (SPVs) following the change in the outlook to negative from stable on the UK's Aa2 sovereign rating on $8^{\text {th }}$ November 2019. SPVs in this case are related to sectors such as local authorities, universities, housing associations, public transit, public sector financing and non-profit organisations.

ii Acharya et al. (2021) in contrast with these studies examine the fire-sale risk channel domestic banks' holdings of sovereign bonds.

iii S\&P (2013). Republic of Turkey unsolicited issue ratings withdrawn. February 14, 2013.

iv Regulation (EC) No 1060/2009 of the European Parliament and of the Council of 16 September 2009 on credit rating agencies.

$\checkmark$ Sovereign analysts often answer judicial questions when their ratings are not met with satisfaction of the governments or regulators (i.e., this is when the ratings are "too low" at any point in time). For example, in 2012 sovereign analysts from S\&P and Fitch were subject to prosecution for market manipulation in a criminal court in Italy following a series of downgrades of that country (Reuters, 2017). Although all the accused were finally acquitted, the process took five years to conclude, which damaged the reputation of the analysts individually as well as the CRAs they represented.

vi We have considered accounting for lawsuits filed against CRAs, however anecdotal evidence suggests that the only CRA of the big three ever charged was S\&P. E.g. See US Department of Justice lawsuits against S\&P in 2013 for misleading analysis on the subprime mortgage sector in 2013 (Reuters, 2013).

vii "ESMA has comprehensive investigatory powers including the possibility to demand any document or data, to summon and hear persons, to conduct on-site inspections and to impose administrative sanctions, fines and periodic penalty payments" EC (2013) available at: https://ec.europa.eu/commission/presscorner/detail/de/MEMO_13_571Since its origination the EU CRA regulator (ESMA) shared fears over revenue generating activities of rating analysts which might pose potential conflict of interest (ESMA, 2014). CRA III regulation requires that CRAs should establish, maintain and document their implementation of policies ensuring the independence of credit ratings, rating analysts and teams (OJEU, 2013; Article 22). Regulation applied some measures to address issues of diversity and independence of credit ratings and opinions including rotations of rating analysts and capping of ownership of rated issuers by CRAs employees. Although regulation is clear that investors are allowed to sue the CRA and not the individual analyst for intentional or gross negligence (Article 33), there have been instances of the latter (Reuters 2013, 2017).

viii The Granger non-causality (GNC) style test examines herding behaviour of CRAs by relative comparison of the probability of a rating change by CRA A conditional on a preceding rating change by CRA $B$. The restriction of relative comparison is due to the fact that rating adjustments are not random events.

ix Fitch is regarded as the CRA with the lowest reputational capital in the context of structured finance products.

$x$ Although Lugo et al. (2015) estimate the relative influence of three Big CRAs in some model specifications their identification strategy assumes that the ratings levels reached a consensus view (it is common knowledge, whereby CRAs take into account the existing rating of their rival CRA when making their own credit assessment). 
xi In Hill and Faff (2010), the leader is the CRA that takes the new information rating actions, i.e. rating changes are in the opposite direction to the preceding change or take the rating level to a new higher (lower) level.

xii For example, there may have been a period where all three CRAs had raised their rating on a sovereign at least once. A change in trend episode would be observed if, after the last of the three agencies had thus raised its rating on the sovereign, all three agencies subsequently lowered their respective rating on the same sovereign (we disregard whether rating actions are taken in steps of single or multiple notches. It is only the direction that matters). This is our practical definition of a turning credit cycle for a specific sovereign, whatever the underlying reason may be. This study looks at this type of trend reversal: the rating trajectory moves into a new direction for all three CRAs.

xiii For instance, the downgrade of France since 2012 from the decades-long 'AAA' rating by all three CRAs.

xiv Although we observe episodes of credit reversal from $1^{\text {st }}$ January 2000, we trace the entire rating history for all sovereigns in our data to pick up the rating events announced before $1^{\text {st }}$ January 2000 . We find five upgrade episodes and one downgrade episode in which the first rating change of an episode occurred before $1^{\text {st }}$ January 2000 . The earliest event was announced in 1997. By doing so, we avoid any possible errors resulting from truncating the time series at $1^{\text {st }}$ January 2000.

xv Outlooks are indications, which often do not lead to actual rating changes. The commonly used definition is that the outlook indicates an "at least one in three" probability that the rating will change in the specified direction. As such the signal is a comparatively weak one. Moody's (2015) state that the time between issuance of outlook and a subsequent rating action can vary depending on the credit developments affecting the issuer and takes a year on average. Credit watch indicates a review for a rating action in a nearer term (30-180 days). Historically these revisions concluded with a rating action over half of the time. Since rating reviews signify only a trajectory of the credit profile, we do not take them into account when identifying reversal of a credit trend to provide a clean setting.

xvi For numerical breakdown of rating categories see Appendix Table A1.

xvii Using S\&P (2020; 2019b) transition reports of sovereigns and corporates we performed back of an envelope exercise to see how long it takes to see the change in credit quality (see Appendix Table A2).

xviii We thank the anonymous referee for a comment regarding discarding events when only one CRA downgrades a sovereign, and no one follows. Sovereign issuers understand that ratings can move up and down. Across the three biggest CRAs there are dozens of rating actions every year in both directions. It is possible that a sovereign could feel mistreated, or misjudged and cancel the contract with the CRA, however we believe that most issuers would not do so as a result of a single event in fear of sending the wrong signal to the markets/fear of their reputation. When sovereigns withdraw from contracts with CRAs they often continue being rated but on a fee-free basis, which has to be publicly disclosed in line with the Article 10 (5) of CRA Regulation. Klusak et al. (2017) has found that those sovereigns who stopped paying receive penalty in the form of higher probability of downgrades on their banks. We feel that sovereigns are more prone to feel aggrieved and "retaliate" by withdrawing a contract if they perceive that one rating agency's actions leads to a more general erosion of their ratings when other agencies follow in the leader's footsteps.

xix The only exception is when Moody's took 1861 days to downgrade Greece (22-Dec-09) following downgrades by S\&P and Fitch (17-Nov-04 and 16-Dec-04).

$x x$ A prominent example of that is the exclusion of S\&P from rating the large inaugural \$12 billion dollar bond in April 2019 issued by Saudi Aramco, the state-owned oil company of the Kingdom of Saudi Arabia, which had previously cancelled the rating contract with S\&P following a first-mover downgrade by that CRA.

xxi Any three global CRAs refer to S\&P, Moody's and Fitch.

xxii The relevance goes beyond losing a single contract as the CRA gains a reputation for being "tough". Rating shopping from issuers can lead to revenue loss of several times the value of the lost contract. Sovereigns are the most visible and arguably important rating group. If sovereign rating coverage shrinks, a CRA loses the position of being "the" leading global rating agency, which is a marketing line used to entice issuers.

xxiii There is a possibility that a contract cancellation is motivated by the sovereign's domestic economic conditions or by the sovereign's dissatisfaction with the initial rating level rather than by the CRA's downgrade actions, we control for this by adding government budget balance (as percentage of GDP), GDP per capita and initial sovereign credit rating level to Eq. (2) and re-estimate it on both full sample and all the samples. Our results are mostly unchanged.

xxiv Additionally, we estimate the Eq. (2) using S\&P revenues for all rating activities globally as dependent variable and find that there is a significant decrease in revenues following a downgrade. The caveat is that we are unable to disentangle between the sovereign rating proceeds separately from the rest of the asset classes. These results are available on request.

xxv Market shares of Moody, Fitch and S\&P do not sum up to $100 \%$.

xxvi Average number of S\&P's sovereign clients lost as a result of a three-notch downgrade is equal to $2.7 \%$ multiplied by 39 (Moody's annual average regional sovereign rating coverage across three regions).

xxvii S\&P region market share refers to the S\&P'S annual region market share defined by the number of sovereigns rated by S\&P as percentage of all sovereigns rated by any three global CRAs in a year. 
xxviii Using revenues earned on ancillary non-rating services, Baghai and Becker (2017) show that there is a commercial interest that results in biased assessments of corporate credit risk in issuer-pay CRAs, which leads to overly high credit ratings and poor ex-post rating performance.

\section{REFERENCES}

Acharya, V., Pierret, D., and Steffen, S. 2021. Lender of last resort, buyer of last resort, and a fear of fire sales in the sovereign bond market. Financial Markets, Institutions and Instruments, 30, 87-112.

Almeida, H., Cunha, I., Ferreira, M. A., and Restrepo, F. 2017. The real effects of credit ratings: The sovereign ceiling channel. Journal of Finance 72, 249-290.

Alsakka, R., and apGwilym, O. 2010. Leads and lags in sovereign credit ratings. Journal of Banking and Finance 34, 2614-2626.

Augustin, P., Boustanifar, H., Breckenfelder, J., and Schnitzler, J. 2018. Sovereign to corporate risk spillovers. Journal of Money, Credit and Banking 50, 857-891.

Baghai, R.P., and Becker, B. 2017. Non-rating revenue and conflicts of interest. Journal of Financial Economics 127, 94-112.

Banerjee, A.V. 1992. A simple model of herd behavior. Quarterly Journal of Economics 107, 797-817.

Barber, B., Lehavy, R., McNichols, M., and Trueman, B. 2001. Can investors profit from the prophets? Security analyst recommendations and stock returns. Journal of Finance 56, 531-56.

Bar-Isaac, H., and Shapiro, J. 2013. Ratings quality over the business cycle. Journal of Financial Economics 108, $62-78$.

Becker, B., and Milbourn, T. 2011. How did increased competition affect credit ratings? Journal of Financial Economics, 101, 493-514.

Berwart, E., Guidolin, M., and Milidonis, A. 2016. An empirical analysis of changes in the relative timeliness of issuer-paid vs. investor-paid ratings. Journal of Corporate Finance, 59, 88-118.

Brunnermeier, M., Garicano, K., Lane, P., Pagano, M., Reis, R., Santos, T., Thesmar, D., Nieuwerburgh, S., and Vayanos, D. 2016. The sovereign-bank diabolic loop and ESBies. American Economic Review 106, 508-12.

Bushee, B. J., Core, J. E., Guay, W., and Hamm, S. J. W. 2010. The role of the business press as an information intermediary. Journal of Accounting Research 48, 1-19.

Camanho, N., Deb, P., and Liu, Z. 2020. Credit rating and competition. International Journal of Finance and Economics. Forthcoming.

Chen, S., Chen, H., Chang, C., and Yang, S. 2016. The relation between sovereign credit rating revisions and economic growth. Journal of Banking and Finance 64, 90-100.

Chen, Q., Hua, X., and Jiang, Y. 2018. Contrarian strategy and herding behaviour in the Chinese stock market. European Journal of Finance 24, 1552-156.

Chen, Z., Matousek, R., Stewart, C., and Webb, R. 2019. Do rating agencies exhibit herding behaviour? Evidence from sovereign ratings. International Review of Financial Analysis 64, 57-70.

Clement, M.B., and Tse, S.Y. 2005. Financial analyst characteristics and herding behavior in forecasting. Journal of Finance 60 , 307-341.

Cooper, R.A., Day, T.E., and Lewis, C.M. 2001. Following the leader: a study of individual analysts, earnings forecasts. Journal of Financial Economics 61, 383-416.

Cornaggia, J.N., Cornaggia, K.J., and Hund, J.E. 2017. Credit ratings across asset classes: A long-term perspective. Review of Finance 21, 465-509.

Da, Z., Larrain, B., Sialm, C., and Tessada, J. 2018. Destabilizing financial advice: Evidence from pension fund reallocations. Review of Financial Studies 31, 3720-3755.

Devenow, A., and Welch, I. 1996. Rational herding in financial economics. European Economic Review 40, 603-615.

Efing, M. and Hau, H. 2015. Structured debt ratings: Evidence on conflicts of interest. Journal of Financial Economics, 116, 4660.

European Commission (EC), 2013. New rules on credit rating agencies (CRAs) enter into force - frequently asked questions. MEMO. June 182013.

European Commission (EC), 2011. Regulation (EC) No 1060/2009 of the European Parliament and of the Council of 16 September 2009 on credit rating agencies. September 162009.

European Securities and Markets Authority (ESMA), 2017. Update of the guidelines on the application of the endorsement regime under Article 4(3) of the credit rating agencies regulation. Final Report. November 17 2017. ESMA 33/9/205.

European Securities and Markets Authority (ESMA), 2014. Credit rating agencies. Annual report. February 212014. ESMA/2014/151.

Fitch, 2020. Sovereign rating criteria. October 2020.

Flynn, S., and Ghent, A. 2018. Competition and credit ratings after the fall. Management Science 64, 1672-1692.

Frijns, B., and Huynh, T.D. 2018. Herding in analysts' recommendations: The role of media. Journal of Banking and Finance 91 , 1-18.

Graham, J. R. 2003. Herding among investment newsletters: Theory and evidence. Journal of Finance 54, $237-268$. 
Griffin, J. M., Nickerson, J., and Tang, D. Y. 2013. Rating shopping or catering? An examination of the response to competitive pressure for CDO ratings. Review of Financial Studies 26, 2270-2310.

Güttler, A. 2011. Lead-lag relationships and rating convergence among credit rating agencies. Journal of Credit Risk 7, 95-119.

Güttler, A., and Wahrenburg, M. 2007. The adjustment of credit ratings in advance of defaults. Journal of Banking and Finance 31, 751-767.

Hill, P., Bissoondoyal-Bheenick, E., and Faff, R. 2017. New evidence on sovereign to corporate credit rating spillovers. International Review of Financial Analysis, 55, 209-225.

Hill, P., and Faff, R. 2010. The market impact of relative agency activity in the sovereign ratings market. Journal of Business Finance and Accounting 37, 1309-1347.

Hong, H., Kubik, J., and Solomon, A. 2000. Security analysts' career concerns and herding of earnings forecasts. Rand Journal of Economics 31, 121-144.

Jegadeesh, N., and Kim, W. 2010. Do analysts herd? An analysis of recommendations and market reactions. Review of Financial Studies 23, 901-937.

Klusak, P., Alsakka, R., and ap Gwilym, O. A. 2017. Does the disclosure of unsolicited sovereign rating status affect bank ratings? British Accounting Review 49, 194-210.

Lugo, S., Croce, A., and Faff, R. 2015. Herding behavior and rating convergence among credit rating agencies: Evidence from the subprime crisis. Review of Finance 19, 1703-1731.

Mählmann, T. 2011. Is there a relationship benefit in credit ratings? Review of Finance 15, 475-510.

Mariano, B. 2012. Market power and reputational concerns in the ratings industry. Journal of Banking and Finance 36, 16161626.

Moody's Investors Service (MIS), 2017. Code of professional conduct. June 2017.

Moody's Investors Service (MIS), 2015. Rating symbols and definitions. March 2015.

Official Journal of the European Union (OJEU) 2013. Regulation (EU) No 462/2013 of the European Parliament and of the Council of 21 May 2013 amending Regulation (EC) No 1060/2009 on credit rating agencies. Regulation Legislative Acts 146/1, May 312013.

Raddatz, C., and Schmukler, S. 2013. Deconstructing herding: Evidence from pension fund investment behavior. Journal of Financial Services Research 43, 99-126.

Rajan, R. 2006. Has financial development made the world riskier? European Financial Management 12, 499-533.

Rees, L., Sharp, N., and Twedt, B. 2014. Who's heard on the Street? Determinants and consequences of financial analyst coverage in the business press. Review of Accounting Studies 20, 173-209.

Reuters, 2017. Italy prosecutor asks for jail sentences for five S\&P managers. January 2017.

Reuters, 2013. S\&P calls federal lawsuit 'retaliation' for U.S. downgrade. September 2013.

SEC, 2013. Report to Congress: Credit rating agency independence study as required by section 939C of the Dodd-Frank Wall Street Reform and Consumer Protection Act. November 2013.

Scharfstein, D., and Stein, J. 1990. Herd behavior and investment. American Economic Review 80, 465-579.

S\&P Global Ratings, 2020. Default, transition, and recovery: 2019 annual global corporate default and rating transition study. April 2020.

S\&P Global Ratings, 2019a. Sovereign ratings history. February 2019.

S\&P Global Ratings, 2019b. Default, transition, and recovery: 2018 annual sovereign default and rating transition study. March 2019.

S\&P Global Ratings, 2019c. Sovereign debt 2019: Global borrowing to increase by 3.2\% to US \$7.8 trillion. February 2019.

S\&P Global Ratings, 2018. S\&P global ratings code of conduct. March 2018.

S\&P Global Ratings, 2017. Sovereign rating methodology. December 2017.

S\&P Global Ratings, 2014. Outlooks: The sovereign credit weathervane, year-end 2013 update. February 2014.

S\&P Global Ratings, 2013. How we rate sovereigns. November 2013.

S\&P Global Ratings, 2011a. Ratings on seven European sovereigns and the European Central Bank converted to unsolicited ratings.

S\&P Global Ratings, 2011b. Ratings on six Asia-Pacific sovereigns converted to unsolicited ratings.

S\&P Global Ratings, 2011c. Ratings on the U.S. Government converted to unsolicited ratings.

Staikouras, P. K. 2012. A theoretical and empirical review of the EU regulation on credit rating agencies: In search of truth, not scapegoats. Financial Markets, Institutions and Instruments 21, 71-155.

Tetlock, P. 2010. Does public financial news resolve asymmetric information? Review of Financial Studies 23, $3520-355$.

Trueman, B. 1994. Analyst forecasts and herding behavior. Review of Financial Studies 7, 97-124.

Wilson, B. K., and Donnellan, J. T. 2016. The technology of ratings then and now; Hiding in plain sight. Financial Markets, Institutions and Instruments 25, 49-74. 
How to cite this article: Klusak P, Kraemer M, Vu H. First-mover disadvantage: the sovereign ratings mousetrap. Financial Markets, Inst \& Inst.. 2022;1-42. https://doi.org/10.1111/fmii.12155

\section{APPENDIX}

TAB LE A 1 The 20-Notch numerical rating scale

\begin{tabular}{|c|c|}
\hline RATING SYMBOLS & 20-POINT SCALE \\
\hline AAA & 20 \\
\hline $\mathrm{AA}+$ & 19 \\
\hline AA & 18 \\
\hline AA- & 17 \\
\hline$A+$ & 16 \\
\hline$A$ & 15 \\
\hline A- & 14 \\
\hline $\mathrm{BBB}+$ & 13 \\
\hline BBB & 12 \\
\hline BBB- & 11 \\
\hline $\mathrm{BB}+$ & 10 \\
\hline BB & 9 \\
\hline BB- & 8 \\
\hline $\mathrm{B}+$ & 7 \\
\hline B & 6 \\
\hline$B-$ & 5 \\
\hline $\mathrm{CCC}+$ & 4 \\
\hline $\mathrm{CCC}$ & 3 \\
\hline CCC- & 2 \\
\hline CC, SD, D & 1 \\
\hline
\end{tabular}

Note: This Table presents the transformation of the alphabetical rating scale to the 20 -notch numerical rating scale. 
TA B LE A2 Global average transition rates(1980-2018): Sovereign vs. corporate

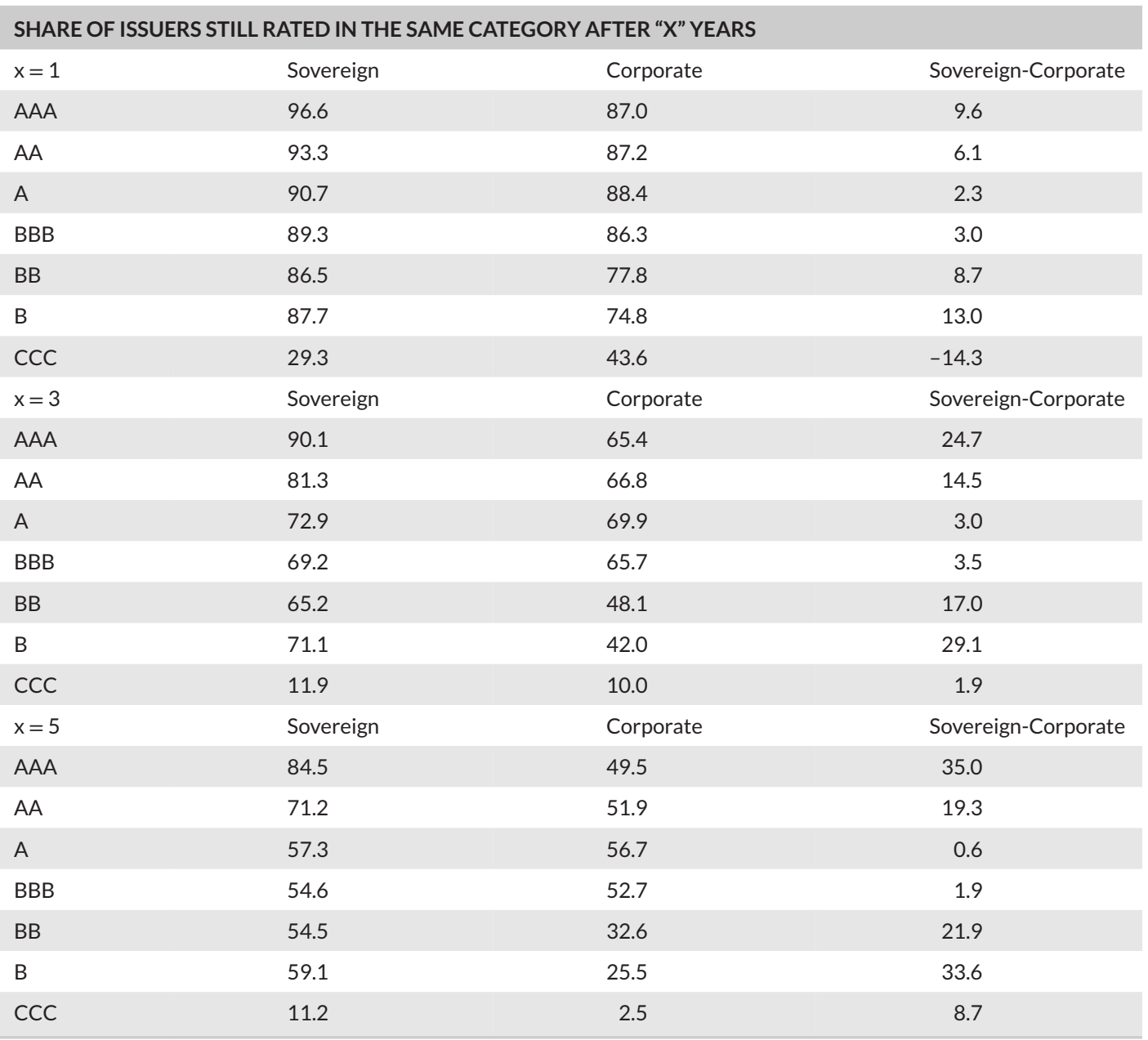

Note: This Table presents transition rates (\%) of sovereign and corporate long-term foreign currency issuer ratings between 1980-2018. Source of data: S\&P (2020; 2019b) transition reports. 


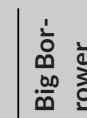

产 융

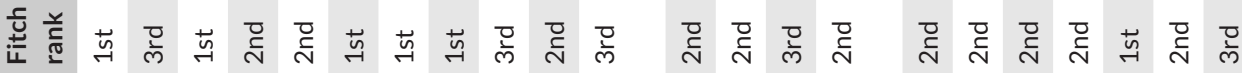
紊

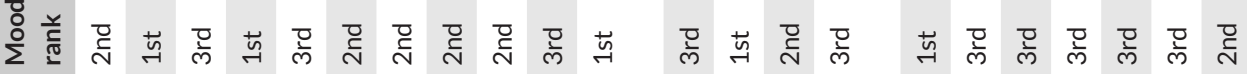

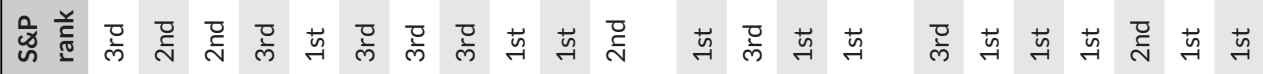

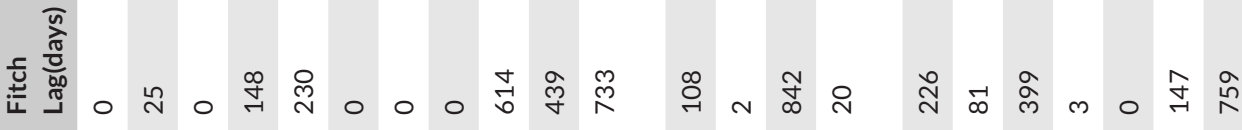

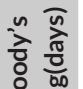

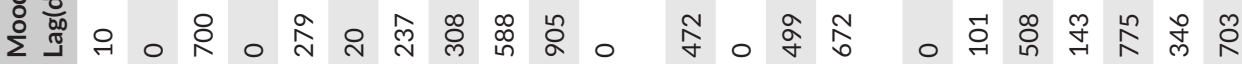
商

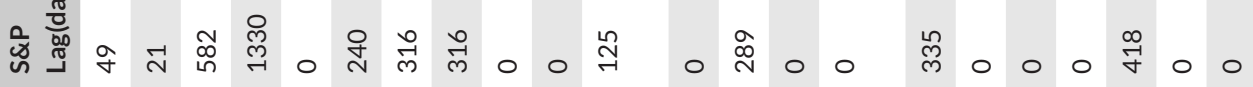

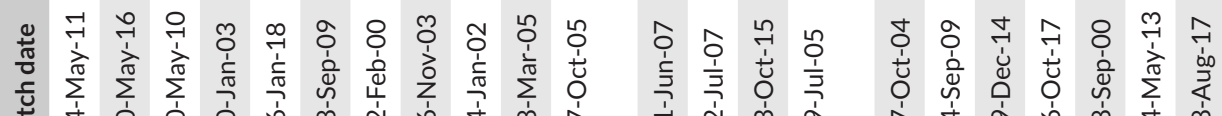

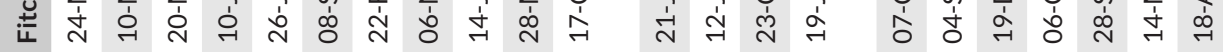

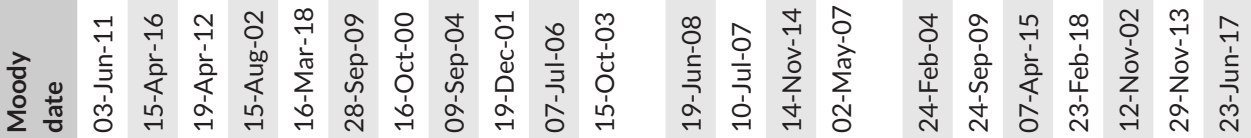

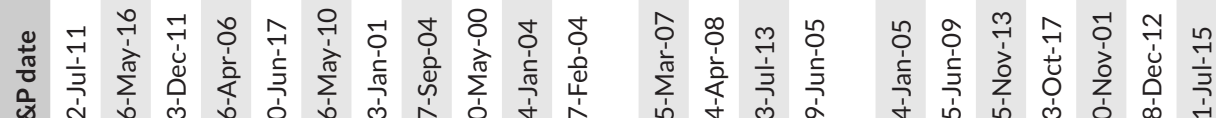

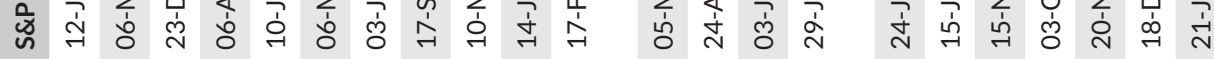

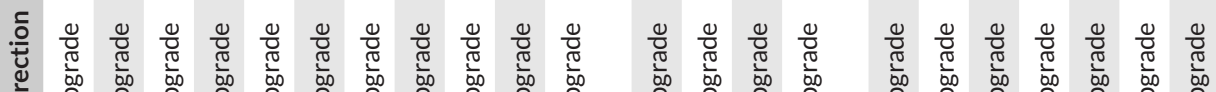

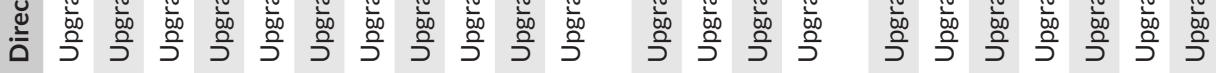

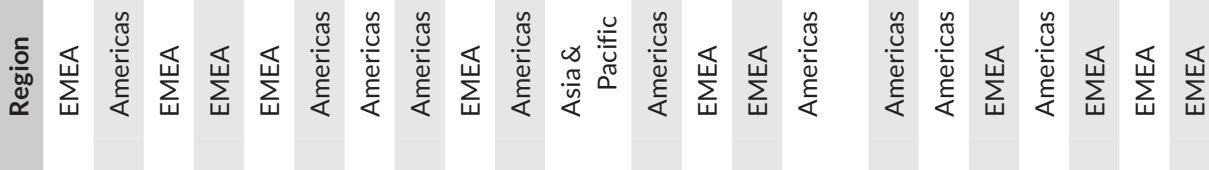

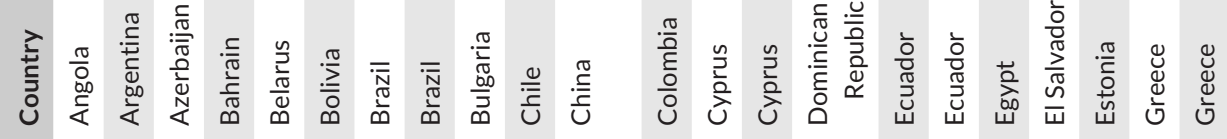




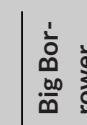

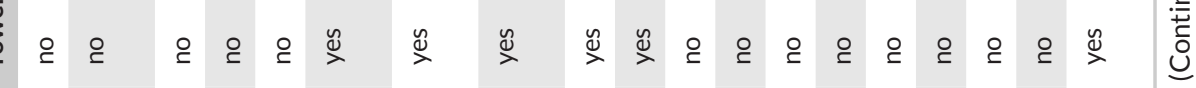

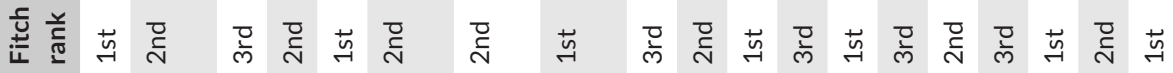

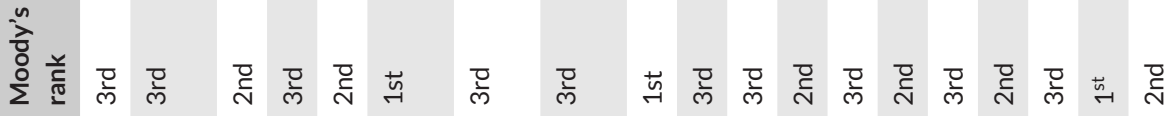

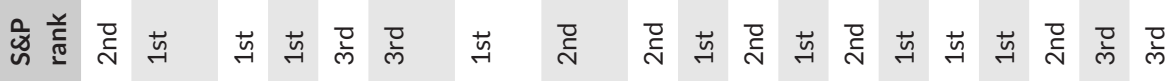

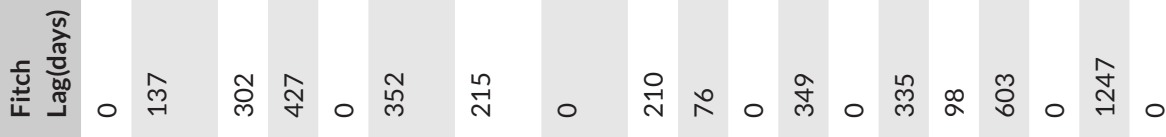

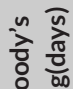

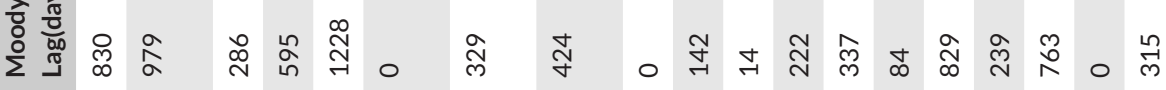

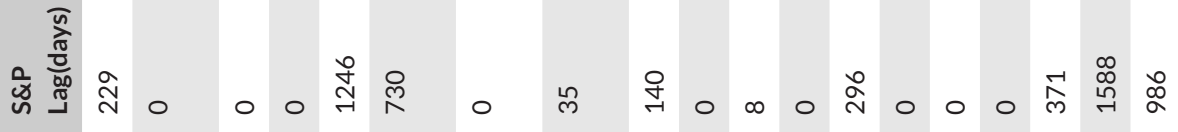

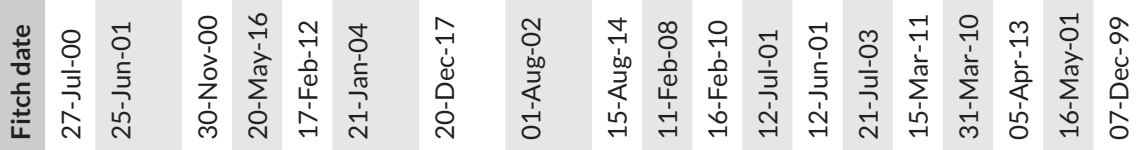

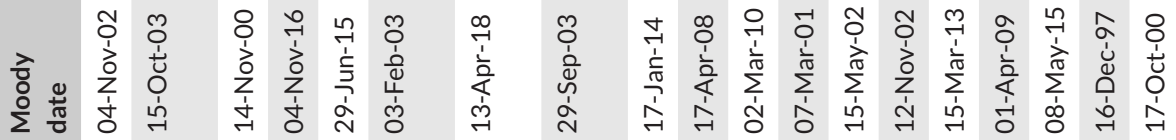

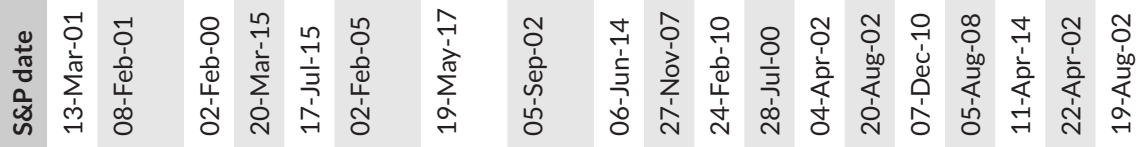

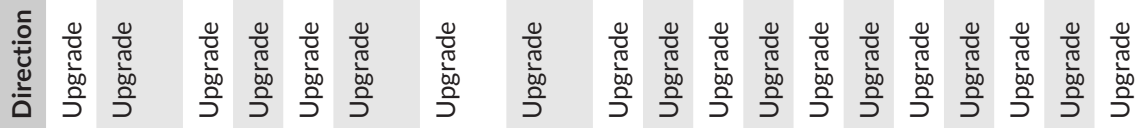

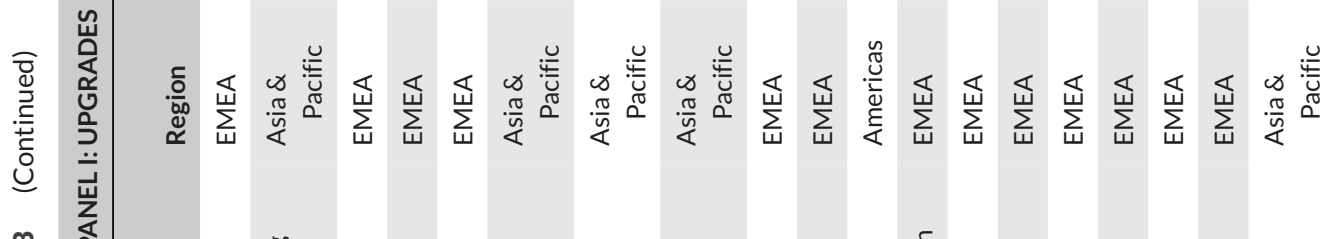

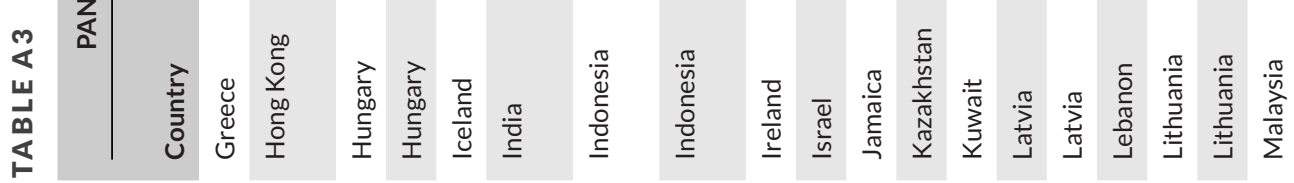


高高高

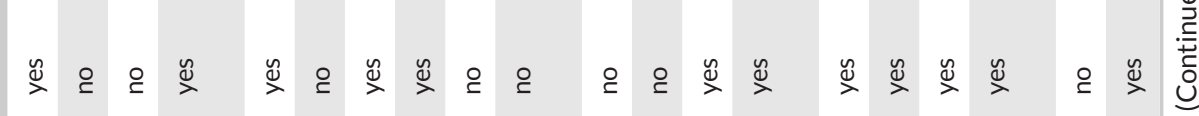

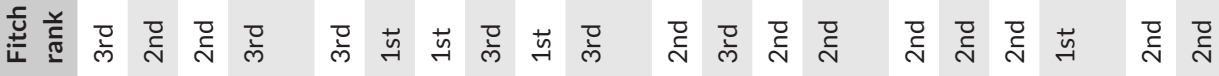

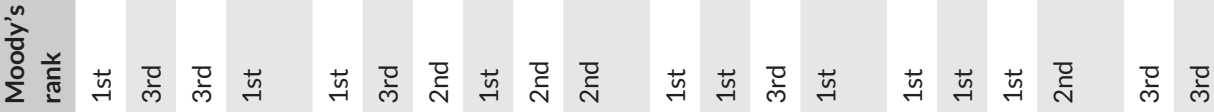

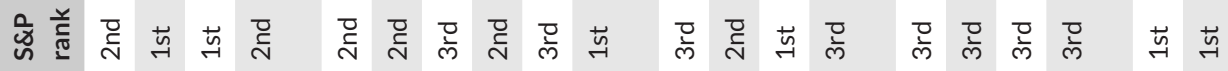

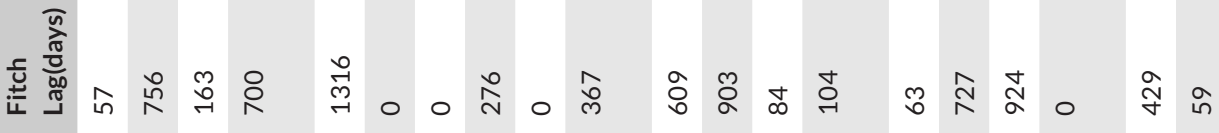

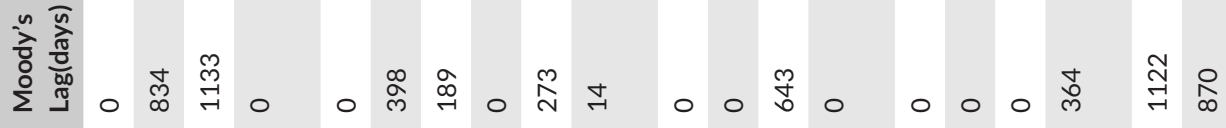

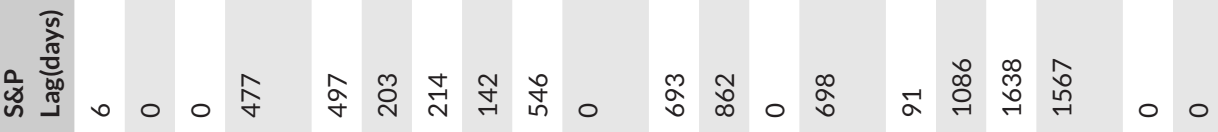

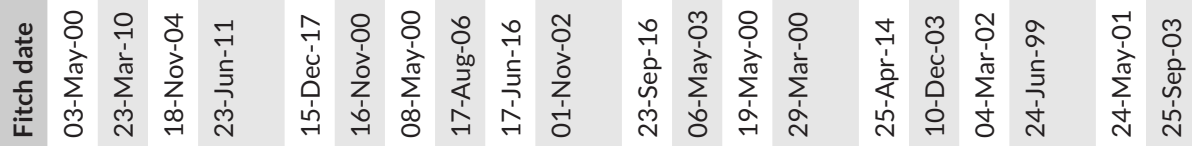

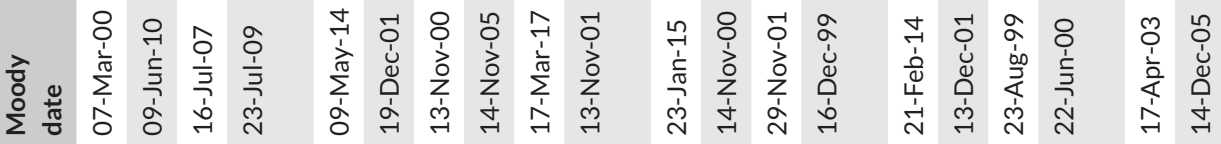
$\begin{array}{llllllllll} & \\ 0\end{array}$

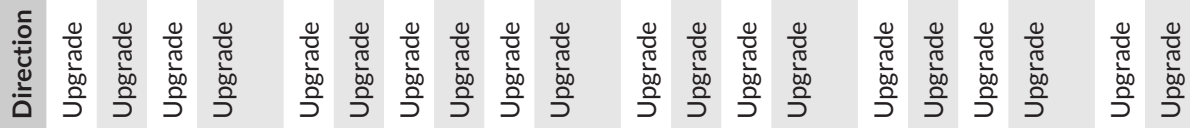

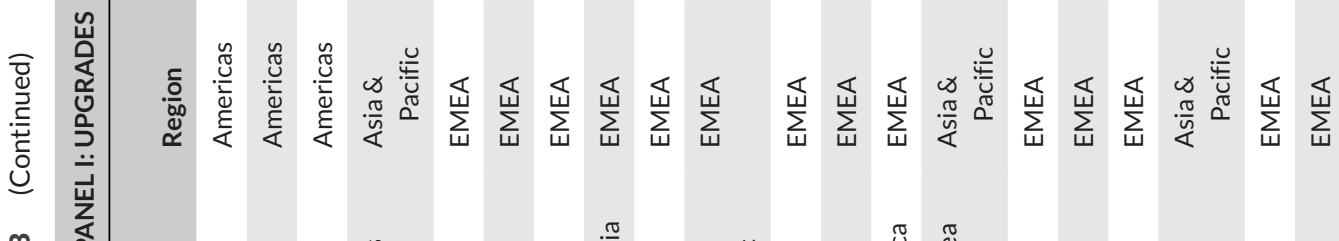

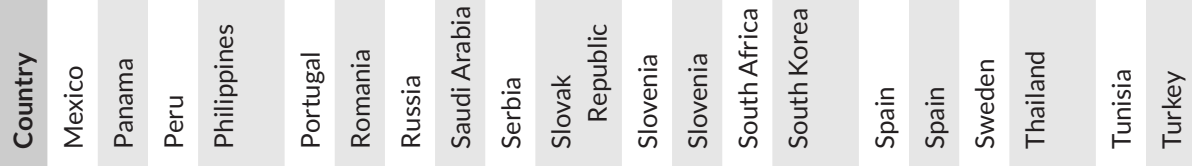




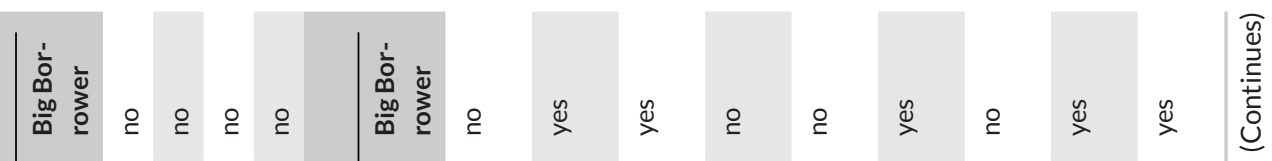

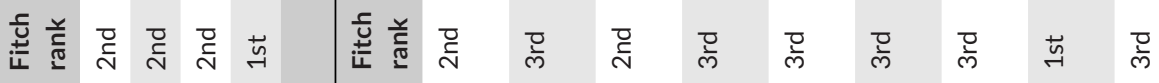

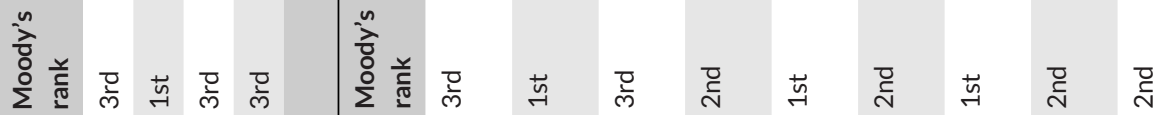

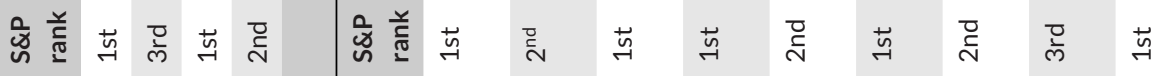

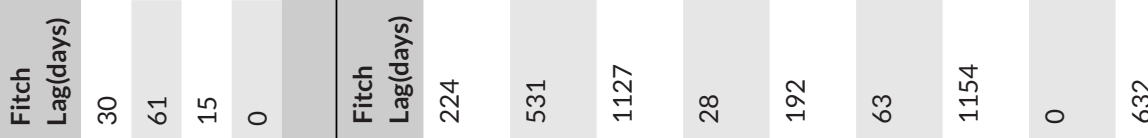

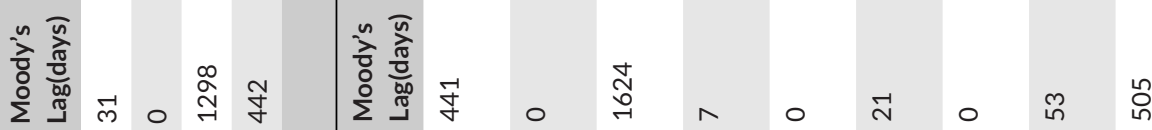

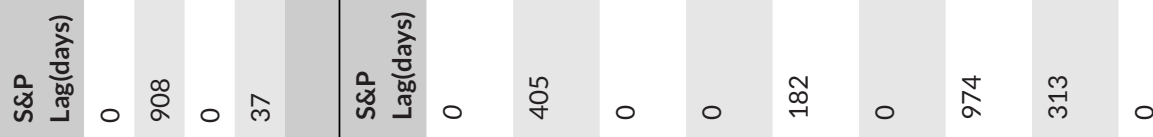

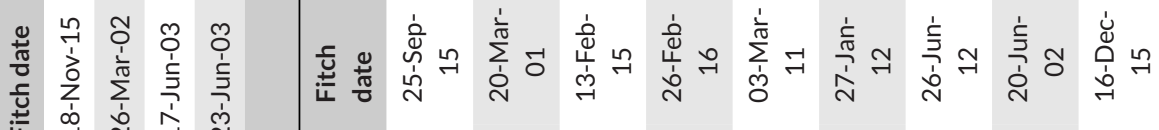

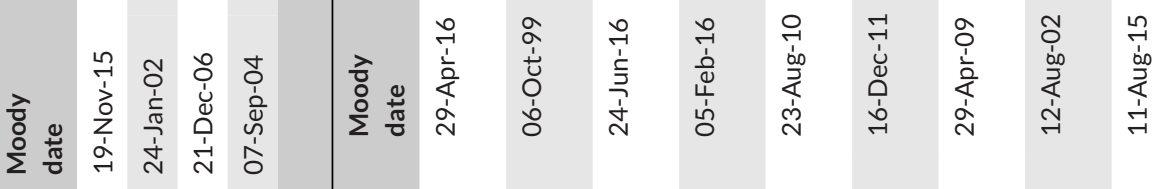

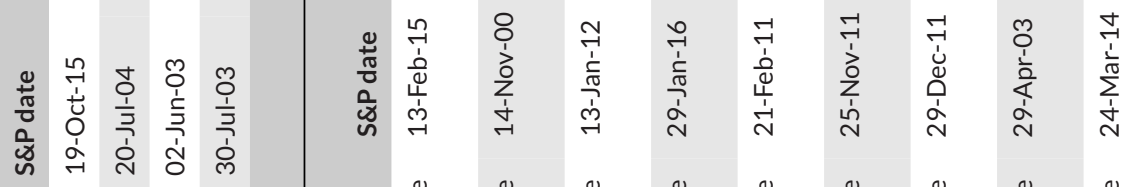

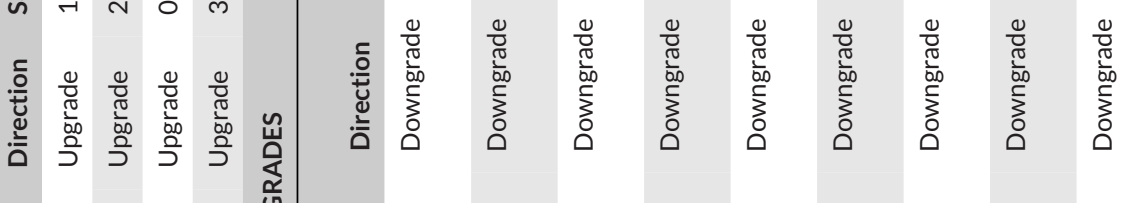

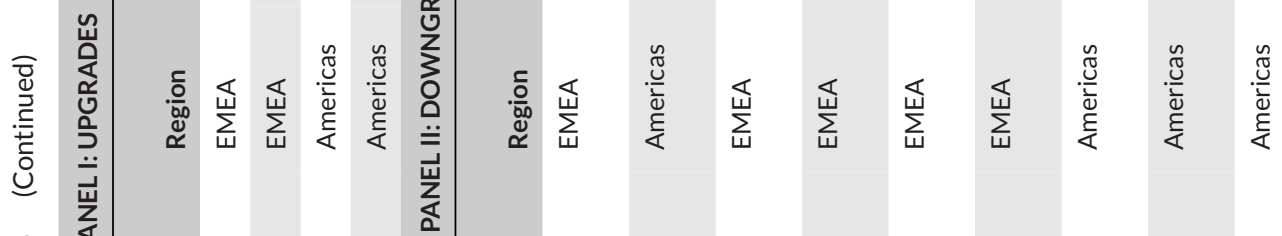

$\underset{4}{m}$

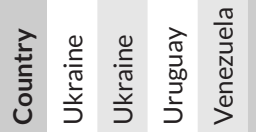

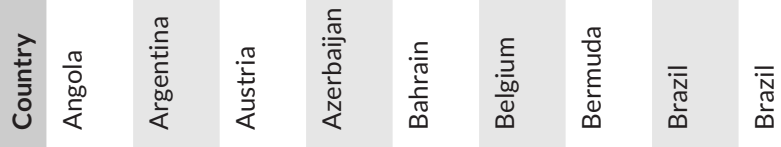




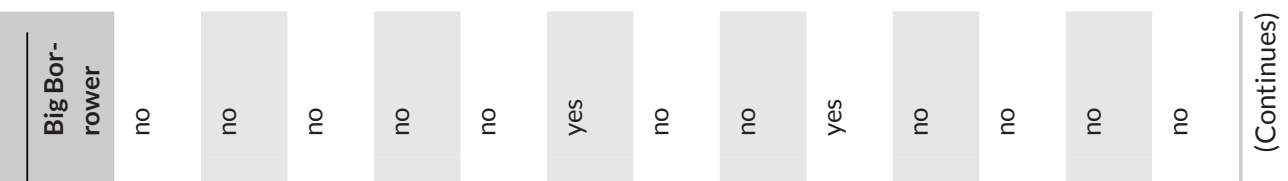

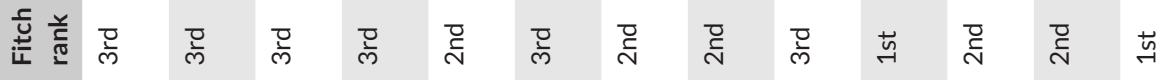

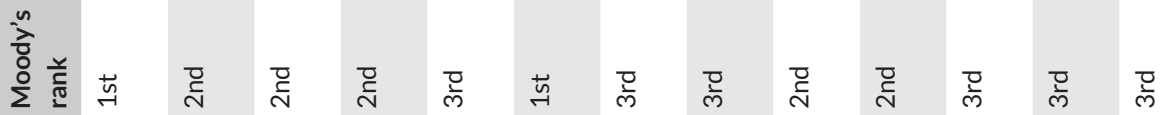

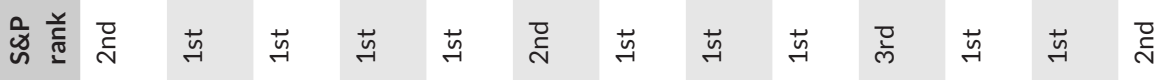

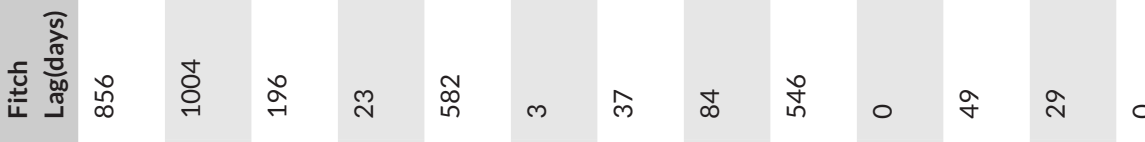

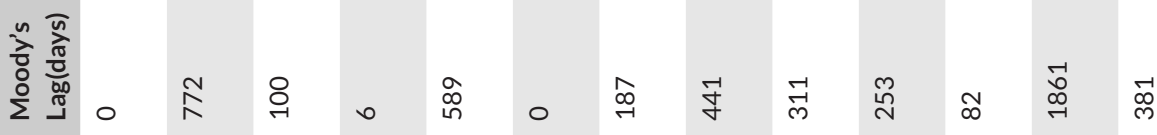

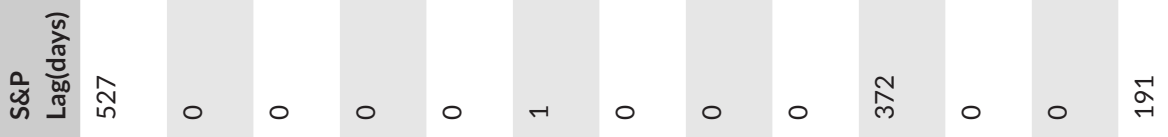

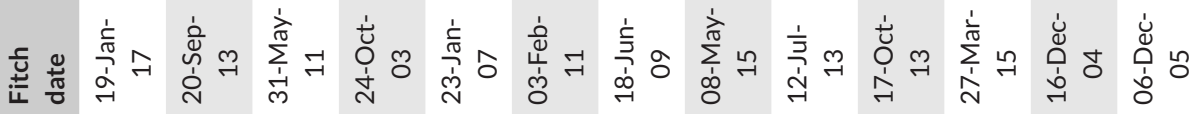

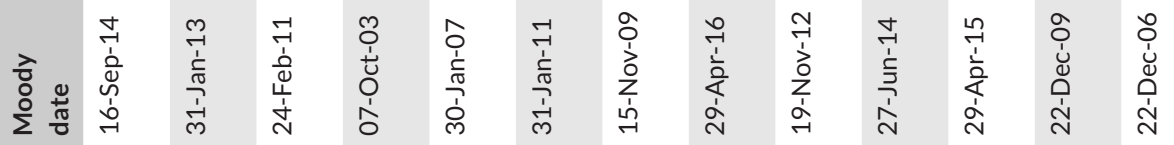

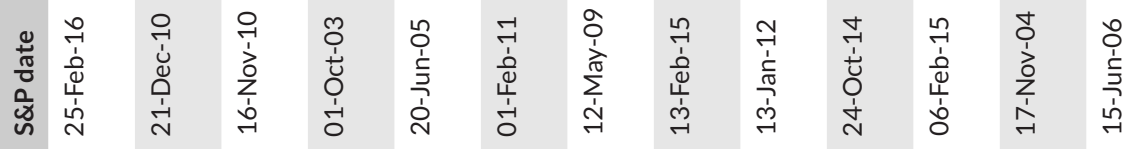

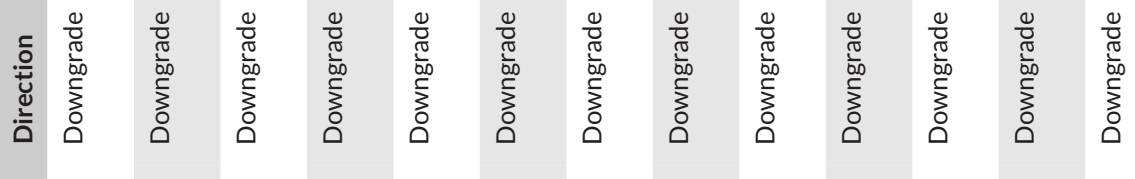

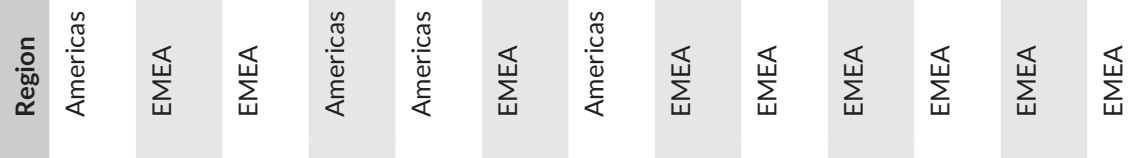

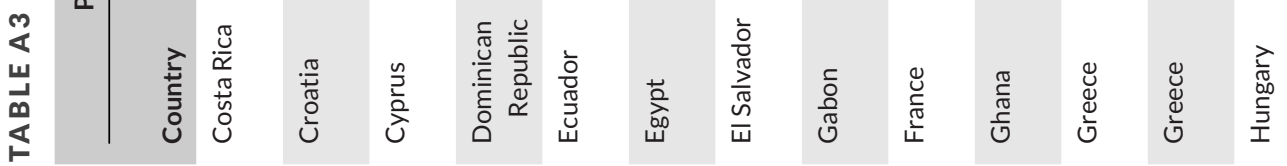




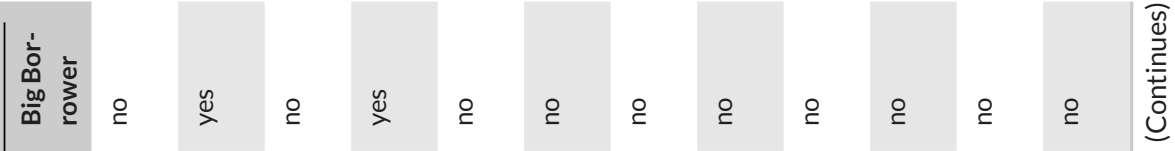

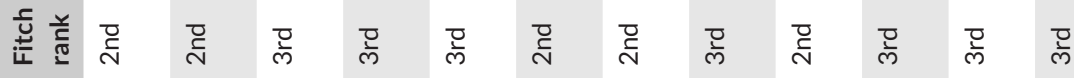

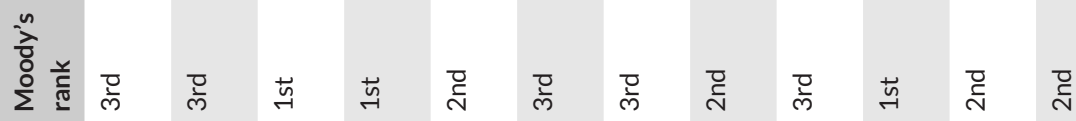

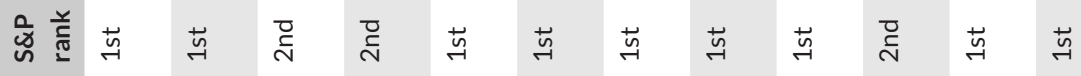

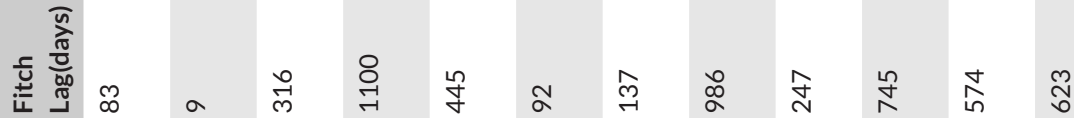

奋

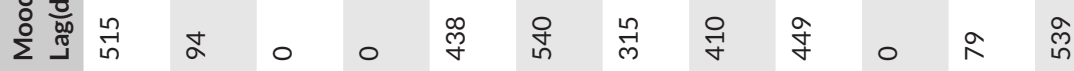

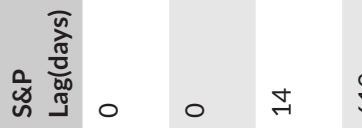

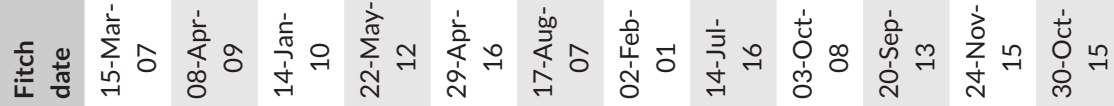

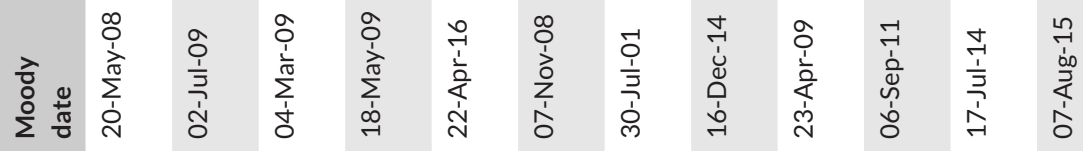

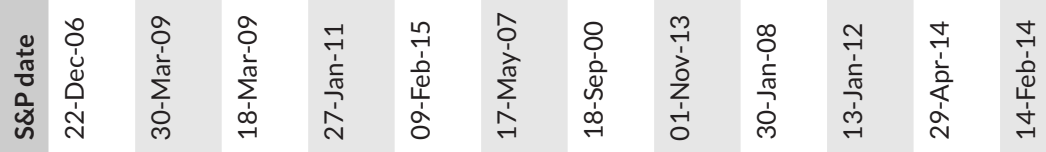

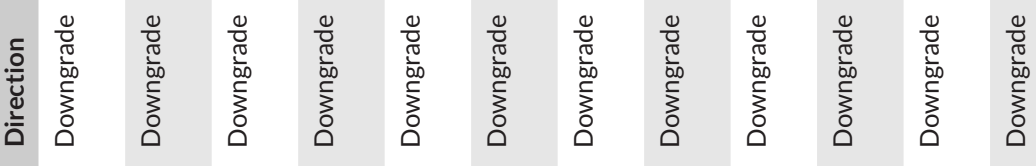

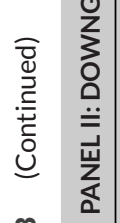

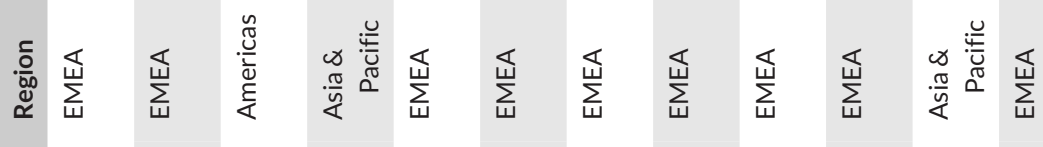

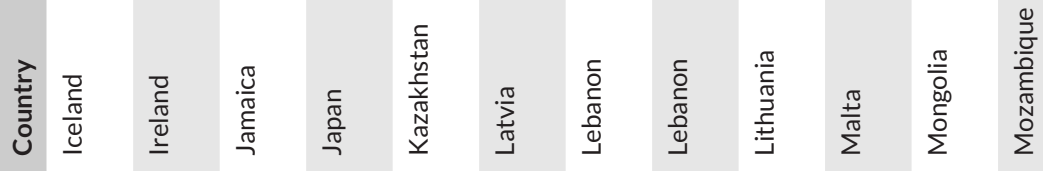




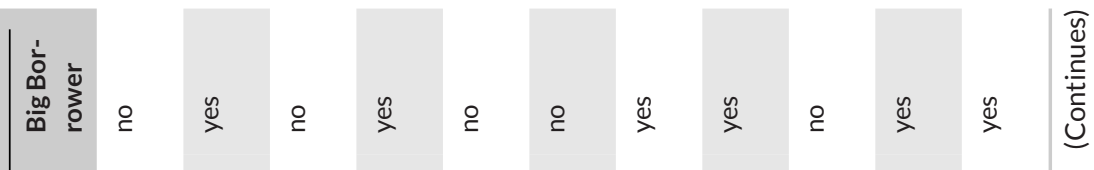

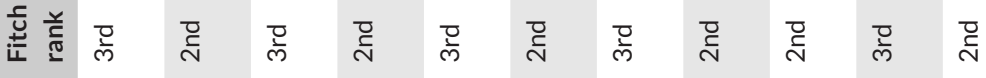

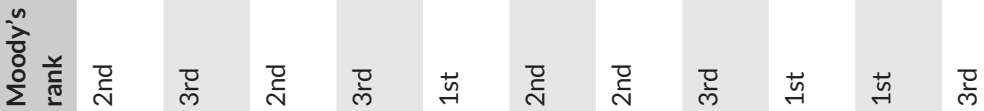

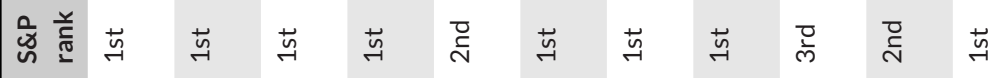

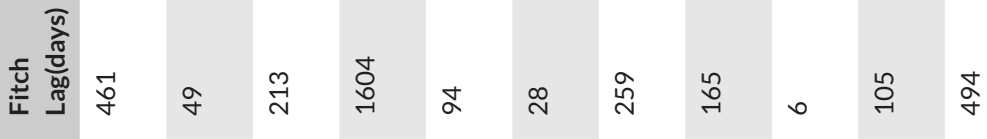

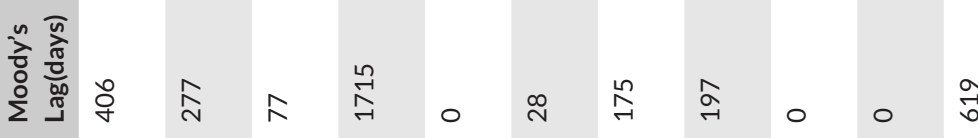

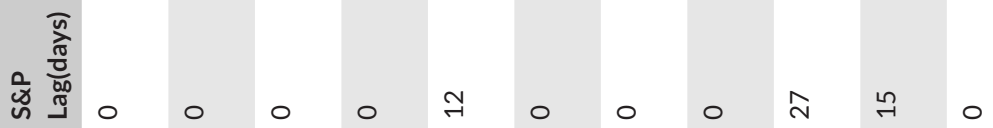

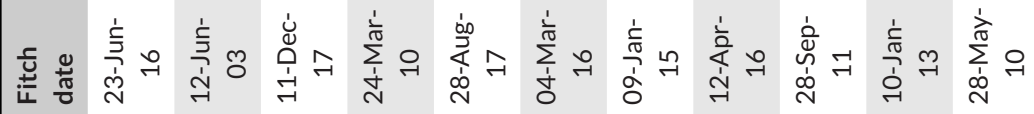

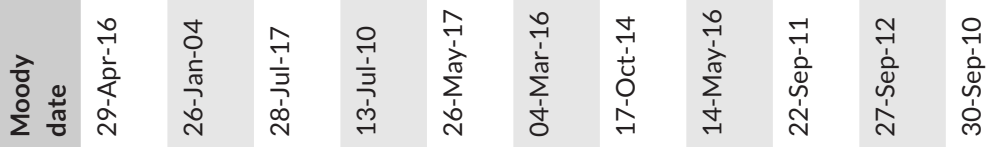

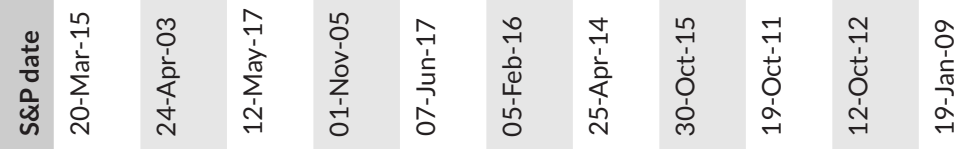

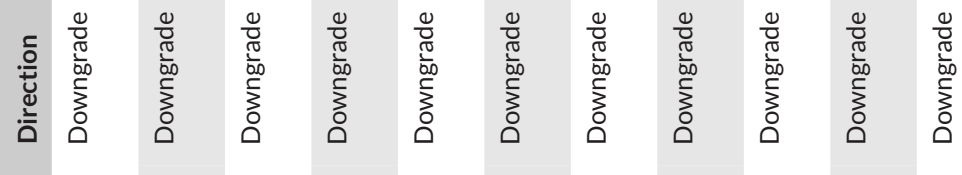

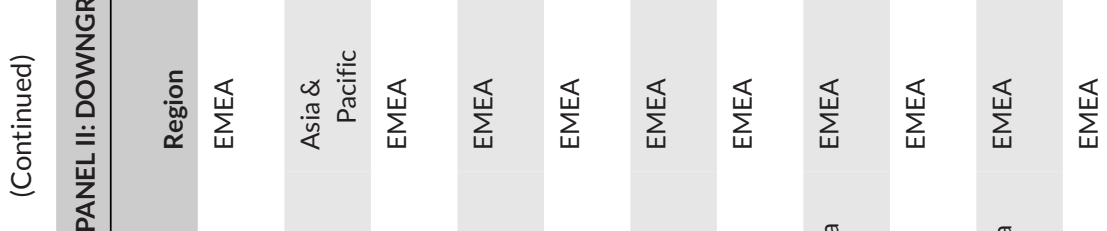

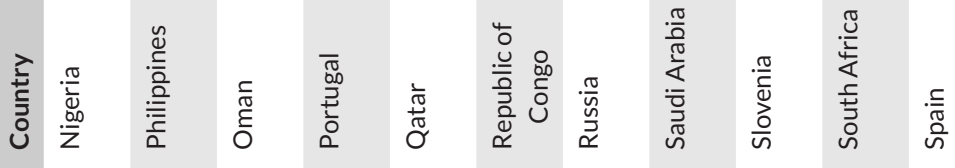




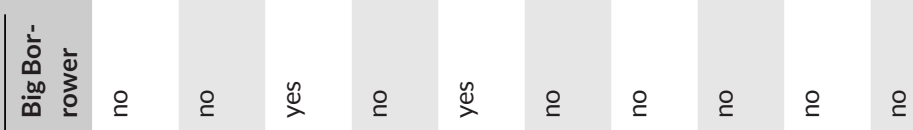

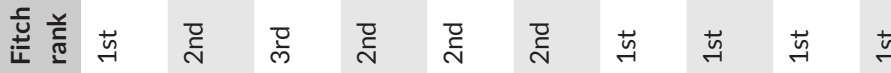

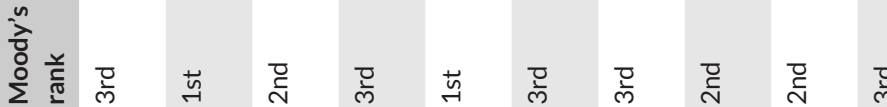

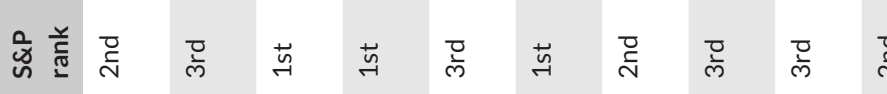

施

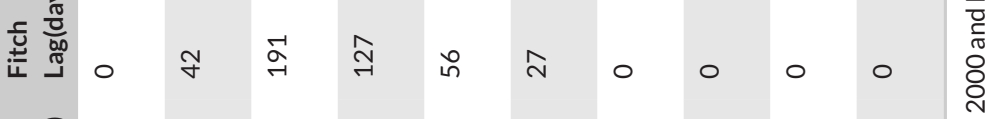

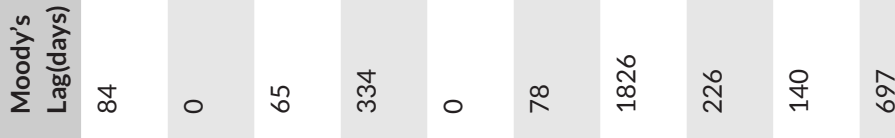

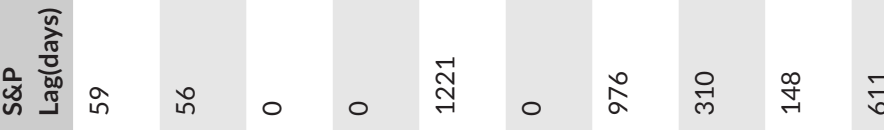

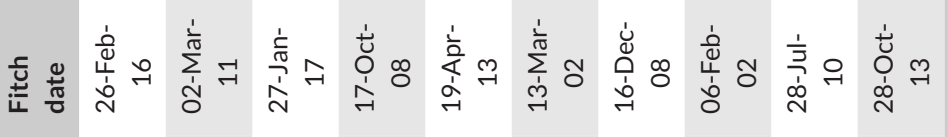

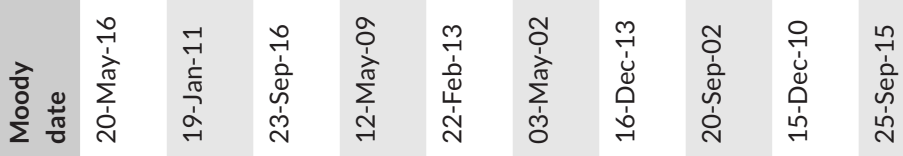

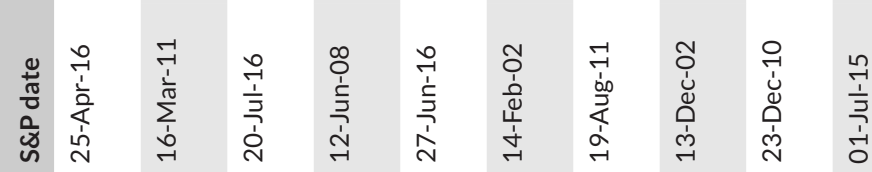

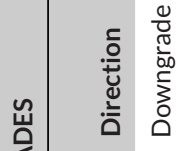

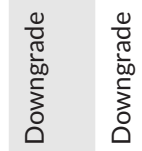

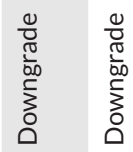

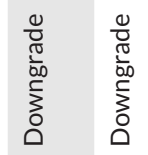

总

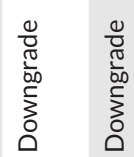

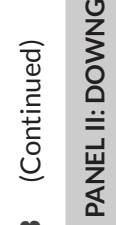

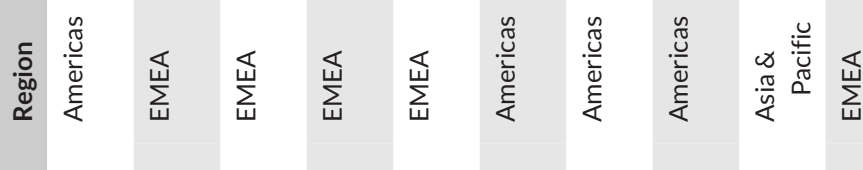

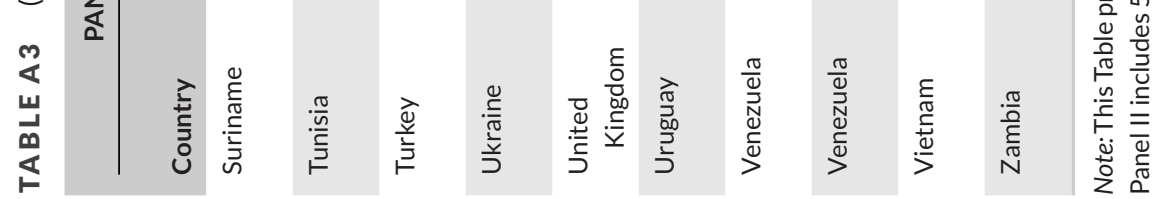




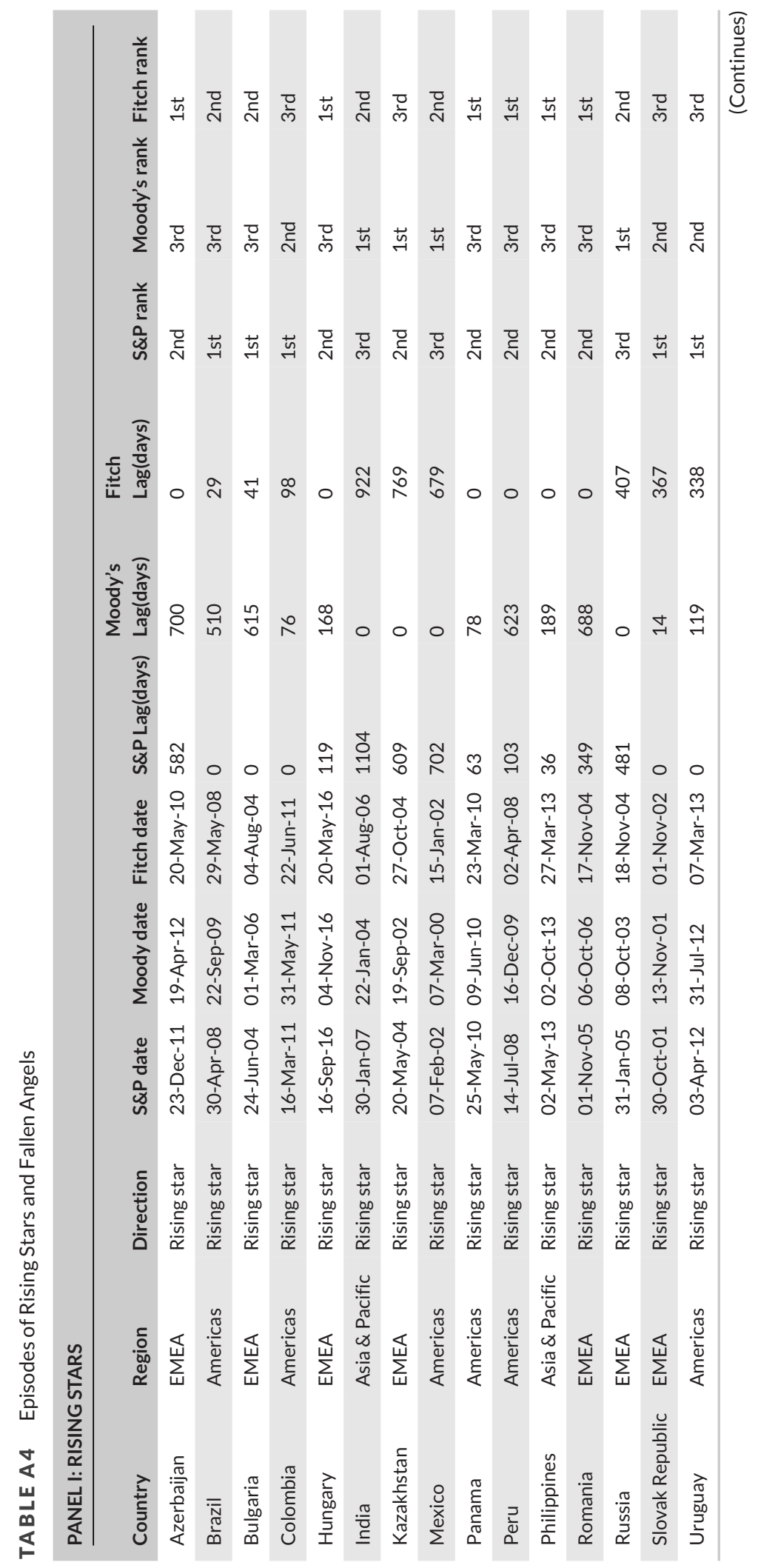




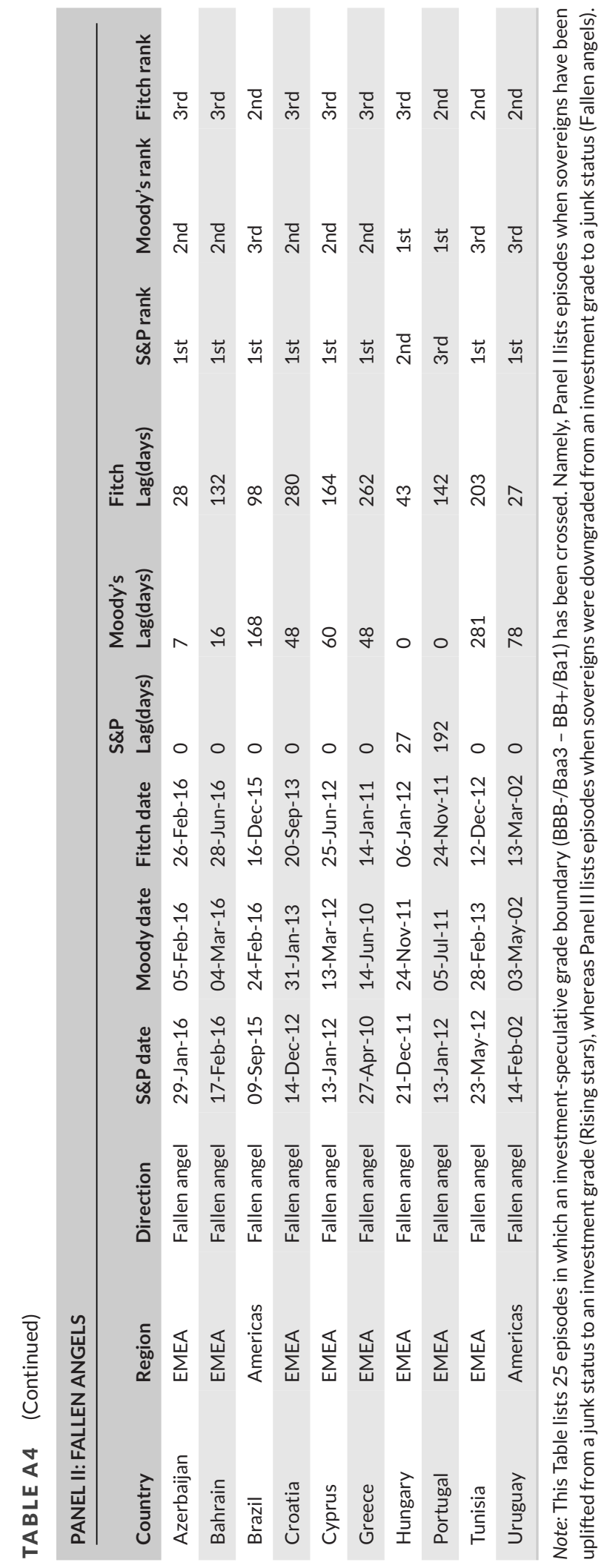

